\title{
Fases de ocupación y estratigrafía del asentamiento neolítico de Les Guixeres de Vilobí (Sant Martí Sarroca, Barcelona)
}

\author{
Phases of occupation and stratigraphy of the Neolithic settlement of Les Guixeres de Vilobi \\ (Sant Martí Sarroca, Barcelona)
}

\author{
F. Xavier Oms ${ }^{\mathrm{a}}$, Josep Mestres ${ }^{\mathrm{b}}$, Héctor Martínez-Grau ${ }^{\mathrm{c}}$, Rafael Laborda ${ }^{\mathrm{d}}$, Ferran \\ Antolín $^{\mathrm{c}}$, M. Mercè Bergadàa, Alejandro Emens ${ }^{\mathrm{a}}$, Juan F. Gibaja ${ }^{\mathrm{e}}$, Cynthia González \\ Olivares $^{\text {a }}$, Xavier Mangado ${ }^{a}$, Patricia Martín ${ }^{a}$, Bàrbara Mas ${ }^{\text {a }}$, Jordi Nadala \\ y Josep M. Fullola
}

\section{RESUMEN}

Les Guixeres de Vilobí (Sant Martí Sarroca, Penedès, Barcelona) es un yacimiento al aire libre de unos $2500 \mathrm{~m}^{2} \mathrm{de}$ extensión, excavados en un $10 \%$ aproximadamente. Su estratigrafía tiene 4 fases documentadas del Neolítico Antiguo Cardial, Neolítico Antiguo Epicardial, Neolítico Postcardial y Neolítico Final. Las ocupaciones se caracterizan por niveles arqueológicos más o menos extensos y por la presencia de numerosas estructuras negativas: agujeros de poste, cubetas, estructuras de combustión, fosas-contenedor y silos. En la fase del Neolítico Cardial, la que tiene más material, se han hallado tres ámbitos que proponemos como unidades habitacionales. Las 9 dataciones radiocarbónicas ( 7 inéditas) que se presentan permiten inferir que las ocupaciones han sido muy continuadas en el tiempo, entre 5600-5200 cal BC para la fase A, c. 5000-4700 cal BC para la fase B, c. 4650-
4450 cal BC para la fase C y c. 3350-3100 cal BC para la fase D. Estos datos cronológicos se completan con los resultados preliminares del análisis de la cultura material del yacimiento. Por último, se presenta especial atención a la comparación de esta con la derivada de las estructuras de hábitat entre el Neolítico Antiguo y el Neolítico Final en diferentes regiones del Mediterráneo occidental.

\begin{abstract}
The open-air site of Les Guixeres de Vilobi (Sant Marti Sarroca, Penedès, Barcelona) has an area of approximately $2,500 \mathrm{~m}^{2}$, of which ca $10 \%$ have been excavated. It has a 4-phase stratigraphy with occupations from the Cardial Early Neolithic, Epicardial Early Neolithic, Postcardial Neolithic and Late Neolithic. These are characterized by
\end{abstract}

Los trabajos en Les Guixeres de Vilobí se insertan en el proyecto cuatrienal "Transicions culturals durant el Plistocè superior i Holocè al litoral-prelitoral central de Catalunya" (CLT009/18/00024, 2018-2021, Generalitat de Catalunya) y en los proyectos del grupo SERP de la Universitat de Barcelona SGR2017-00011 (Generalitat de Catalunya) y HAR2017-86509 (Ministerio de Ciencia, Innovación y Universidades) (IP JMF). La investigación de HM-G y FA se enmarca en el proyecto "Small seeds for large purposes: an integrated approach to agricultural change and climate during the Neolithic in Western Europe", financiado por el SNSF (PP00P1_170515, IP FA) y la de JFG en el proyecto "La difusión del Neolítico en el Mediterráneo centro-occidental: agricultura, innovaciones tecnológicas y carbono 14" (HAR2016-75201-P) del que es investigador principal. PM es contratada postdoctoral Juan de la Cierva (FJCI-2016-29045). CGO es investigadora predoctoral APIF-UB.

a Seminari d'Estudis i Recerques Prehistòriques (SERP). Secció de Prehistòria i Arqueologia, Dept. d'Història i Arqueologia, Facultat de Geografia i Història. Universitat de Barcelona. Carrer de Montalegre 6. 08001 Barcelona. Correos e.: FXO oms@ub.edu (autor de correspondencia) https://orcid.org/0000-0002-1642-548X ; MMB bergada@ub.edu https://orcid.org/0000-0003-3637-7793; AE c.a.emens@hotmail.com https://orcid.org/0000-0002-9492-1366; CGO cynthia.gonzalez@ub.edu https://orcid.org/0000-0002-6075-2322; XM mangado@ub.edu https://orcid.org/0000-0002-3594-0794; PM patricia.martin@ub.edu https://orcid.org/0000-0002-8781-7966; BM barbara.mas86@gmail.com https://orcid.org/0000-0003-2920-638X; JN jordinadal@ub.edu https:/orcid.org/0000-0003-1305-617X; JMF fullola@ub.edu https://orcid.org/0000-0001-7089-1425

b VINSEUM, Museu de les Cultures del Vi. Nostra Senyora 13. 08720 Vilafranca del Penedès. Correo e.: josepmestres@hotmail.com https://orcid.org/0000-0002-7839-7082

c Integrative Prehistoric and Archaeological Science (IPAS), Department of Environmental Sciences, University of Basel, Bernoullistrasse 30 CH4056 Basel. Correos e.: HM hector.martinezgrau@unibas.ch https://orcid.org/0000-0002-5839-3084; FA ferran.antolin@unibas.ch https://orcid.org/0000-0002-0533-5788

d Arqueólogo independiente. Correo e.: rafaellaborda@gmail.com https://orcid.org/0000-0002-0925-6390

e Escuela Española de Historia y Arqueología en Roma (EEHAR-CSIC). Via di Torre Argentina 18. 00186 Roma. Italia. Correo e.: jfgibaja@imf.csic.es https://orcid.org/0000-0002-0830-3570

Recibido 18-I-2021; aceptado 3-VI-2021. de uso y distribución "Creative Commons Reconocimiento 4.0 Internacional” (CC BY 4.0) 
more or less extensive archaeological layers (depending on the phase) and by numerous negative structures: post holes, hearths, pits, and silos. The Cardial Neolithic phase is the richest in terms of material and also has three areas that we suggest are housing units. 9 radiocarbon dates (7 unpublished) indicate that the occupations were almost continous, between 5600-5200 cal BC for phase A, ca 5000-4700 cal $B C$ for phase $B$, ca 4650-4450 cal $B C$ for phase $C$ and $c a$ 3350-3100 cal BC for phase D. To complement these information, preliminary data on the material culture of the site are shown. Finally, these data are combined with to the information derived from the habitat structures between the Early to Late Neolithic in other regions of the western Mediterranean.

Palabras clave: península ibérica; Penedès; Neolítico; asentamiento al aire libre; estratigrafía.

Key words: Iberia; Penedès region; Neolithic; open-air settlement; stratigraphy.

\section{INTRODUCCIÓN}

En los últimos años, la investigación ha prestado mayor atención a los asentamientos prehistóricos al aire libre, que anteriormente estaba más fijada en las cuevas y abrigos (Jover et al. 2019). En el noreste de la península ibérica y en otras regiones, las excavaciones preventivas han dejado al descubierto numerosos yacimientos neolíticos, en su mayoría de los denominados campos de silos. Algunos podrían haber sido más complejos, pero la destrucción de los niveles de circulación impide la documentación de estructuras de escasa potencia (p. ej. pequeños agujeros de poste, cubetas, estructuras de combustión, etc.) o incluso positivas (muros, grill-plants, etc.). Por ese motivo, en términos generales, durante el Neolítico Antiguo es difícil encontrar en la península ibérica yacimientos al aire libre con una articulación compleja del espacio.

La Draga (Banyoles, Girona), los Castillejos (Montefrío, Granada), Mas d'Is (Penáguila, Alicante), Plansallosa (Tortellà, Girona), Xarez 12 (Monsaraz, Alentejo), Los Cascajos (Los Arcos, Navarra), Tossal de les Basses (Alicante), Barranc d'en Frabra (Amposta, Tarragona) o Prazo (Vilanova de Foz Côa, región Norte Tras-os-Montes) son algunos de los asentamientos donde se preservan estructuras habitacionales claramente asociadas a niveles arqueológicos coetáneos (Bosch et al. 1998, 2000; García Gazolaz y Sesma, 2010; Gonçalves et al. 2013; Rosser y Soler 2016; Jover y Torregrossa 2017). Esta dinámica es parecida a la del sur de Francia (Beeching y Sénépart 2009) y contraria a la de buena parte de Italia, donde sobresale la variedad arquitectónica, morfológica y de tamaño de los asentamientos (Pessina y Tiné 2010; Gernigon 2016; Guilaine 2016).

Les Guixeres de Vilobí (a partir de ahora Les Guixeres) es un yacimiento al aire libre al menos con cuatro fases superpuestas de ocupación. La más antigua es la mejor conservada. Las demás tienen una potencia menor, resultado de procesos erosivos y, probablemente, de su menor intensidad de ocupación. Estas cuatro ocupaciones se reparten en dos niveles claramente diferenciables de hasta $130-140 \mathrm{~cm}$ de potencia en algunos tramos del yacimiento. En este trabajo se dan a conocer los datos estratigráficos generales del yacimiento y sus problemas tafonómicos, la especificidad de cada una de las cuatro ocupaciones y sus estructuras asociadas. También se presentan las 9 dataciones radiocarbónicas disponibles en este momento, contextualizadas con los datos preliminares de la cultura material y de los restos bioarqueológicos. Todos ellos serán objeto de futuros estudios monográficos.

\section{LES GUIXERES DE VILOBÍ}

Les Guixeres se sitúa en la comarca del Alt Penedès, en el NE de la península ibérica (Fig. 1), en la vertiente S-SE de un montículo de calizas con intercalaciones de dolomías del Cretácico inferior en un entorno de yesos y calcarenitas del Mioceno. Se alza entre 325-327 m s. n. m. sobre el llano del Penedès, en el municipio de Sant Martí Sarroca (Alt Penedès, Barcelona), a escasos $1100 \mathrm{~m}$ del lecho actual del río Foix. El yacimiento se ha localizado en uno de los escalonamientos naturales del montículo, rodeado de lagunas endorreicas (en un marco de arcillas cuaternarias), desecadas y canalizados en los últimos 150 años para el cultivo de vid.

Martí Grivé (aficionado y erudito local) reconoció el sitio por primera vez en 1932, interpretándolo como

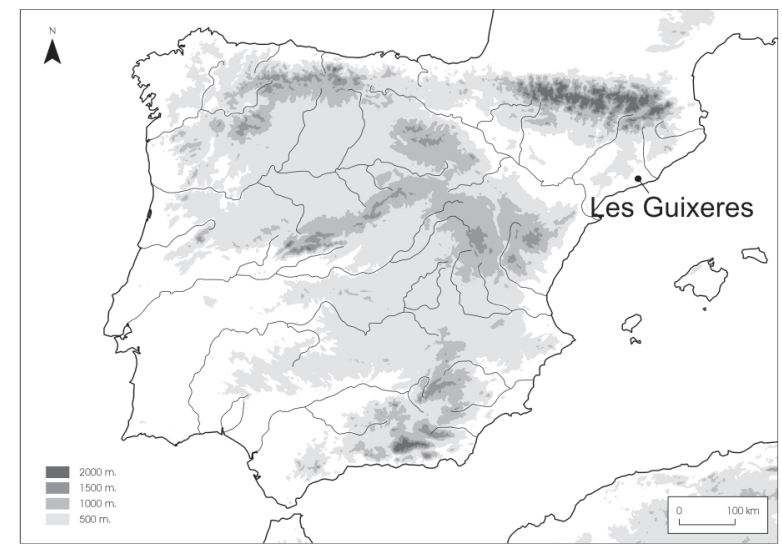

Fig. 1. Situación de Les Guixeres de Vilobí (Sant Martí Sarroca, Barcelona) en la península ibérica y la región catalana del Alt Penedès.

Trab. Prehist., 78, N. ${ }^{\circ}$ 2, julio-diciembre 2021, pp. 257-276, ISSN: 0082-5638

https://doi.org/10.3989/tp.2021.12275 
un taller de sílex con cerámicas cardiales en superficie (Ferrer 1954). En 1973, Vicente Baldellou (entonces) profesor de la Universitat de Barcelona y el (entonces) estudiante Josep Mestres, interesados por el yacimiento, lo prospectaron situando tridimensionalmente y recogiendo una colección ingente de cerámicas cardiales, postcardiales e industria lítica en sílex entre otros restos arqueológicos, extendidos por una superficie de unos $2500 \mathrm{~m}^{2}$. En 1974 realizaron 4 catas o sondeos que afectaron un total de $31 \mathrm{~m}^{2}$. La cata 1 proporcionó la información más relevante, incluyendo los primeros datos sobre la cronología relativa del yacimiento. A partir de ella se propusieron las primeras hipótesis sobre la existencia de un hábitat complejo al aire libre del Neolítico Antiguo. La documentación de una gran depresión alargada rellena de bloques, algunos termoalterados, y de materiales arqueológicos, rodeada por un espacio con menor volumen de material y estructuras, se interpretó como una cabaña semiexcavada con una larga utilización (Baldellou y Mestres 1981; Mestres 1981-1982).

Uno de los firmantes (JM) retomó los trabajos arqueológicos de 1981 a 1984 . Durante estas cuatro campañas, ya dirigidas solo por él, la zona excavada en 1974 se amplió con sucesivos sondeos a su alrededor (catas 5, 6, 7, 8 y 9), con su prolongación hasta la línea 53 y con un sondeo más alejado que extendía la cata 4 inicial (líneas 67 y 68) (Fig. 2). En todas estas campañas se excavaron $120 \mathrm{~m}^{2}$ y se halló un conjunto muy amplio de materiales arqueológicos. Sin embargo, los datos publicados se limitaron a la industria lítica de las tres fases principales (Mestres 1987), a parte de la fauna (Miró 1992) y a la materia prima empleada en las cerámicas postcardiales en un artículo de ámbito regional (Clop 1996). Recientemente se ha estudiado la funcionalidad y la distribución espacial de los útiles líticos de una muestra de Les Guixeres en relación con posibles áreas de actividad (Gibaja et al. 2018).
Durante los años sin excavaciones, se continuó analizando el rico conjunto de datos arqueo-estratigráficos procedentes de las campañas realizadas. Se detectó que la estructura semienterrada citada era parte de la estratigrafía, lo que suponía que el yacimiento era más complejo de lo que se preveía.

En 2015 la Universitat de Barcelona, bajo la dirección de dos de los firmantes (FXO y JM), reemprendió las campañas arqueológicas. Hasta la fecha han sido cinco, sumándose a la dirección HM-G y RL. Se ha ampliado la zona excavada hasta los años 80 en unos $80 \mathrm{~m}^{2}$ y durante la campaña de 2019 se realizó un sondeo a $25 \mathrm{~m}$ al norte de esa zona (Fig. 2) para comprobar si se conservaba estratigrafía con resultados positivos.

Desde su inicio, las excavaciones emplearon cuadrículas y coordenadas cartesianas. Los materiales se proyectaron también cada $50 \mathrm{~cm}$ en diferentes secciones NS y EO ante la falta de resolución de visu de los niveles arqueológicos en el registro sedimentario. El procedimiento permite identificar posibles estructuras negativas, indetectables durante el trabajo de campo, y delimitar mejor la potencia y extensión de las fases de ocupación. Desde la campaña de 2015 se llevan a cabo muestreos aleatorios de un mínimo de 20 litros de sedimento por estructura o cuadro excavado, destinadas a recuperar restos carpológicos y antracológicos.

\section{SECUENCIA ESTRATIGRÁFICA DE LES GUIXERES DE VILOBÍ}

Una de las particularidades de este yacimiento al aire libre es la superposición de ocupaciones del Neolítico Antiguo Cardial (Fase A), Neolítico Antiguo Epicardial (Fase B), Neolítico Postcardial (Fase C) y Neolítico Final (Fase D). De techo a base se han localizado dos niveles en la secuencia edafosedimentaria (Fig. 3A):

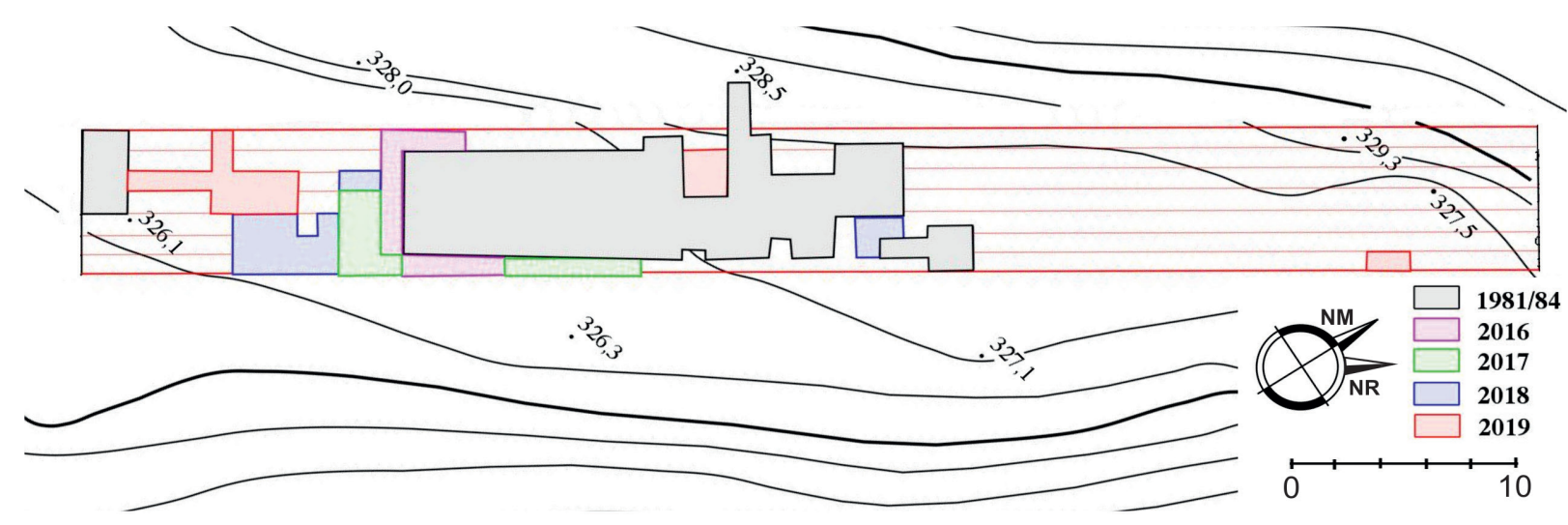

Fig. 2. Les Guixeres de Vilobí. Planta de las actuaciones arqueológicas desde el año 1981 (autoría Mestres, Oms, Martínez-Grau y Laborda). Distancia entre curvas de nivel: $5 \mathrm{~m}$. En color en la edición electrónica. 

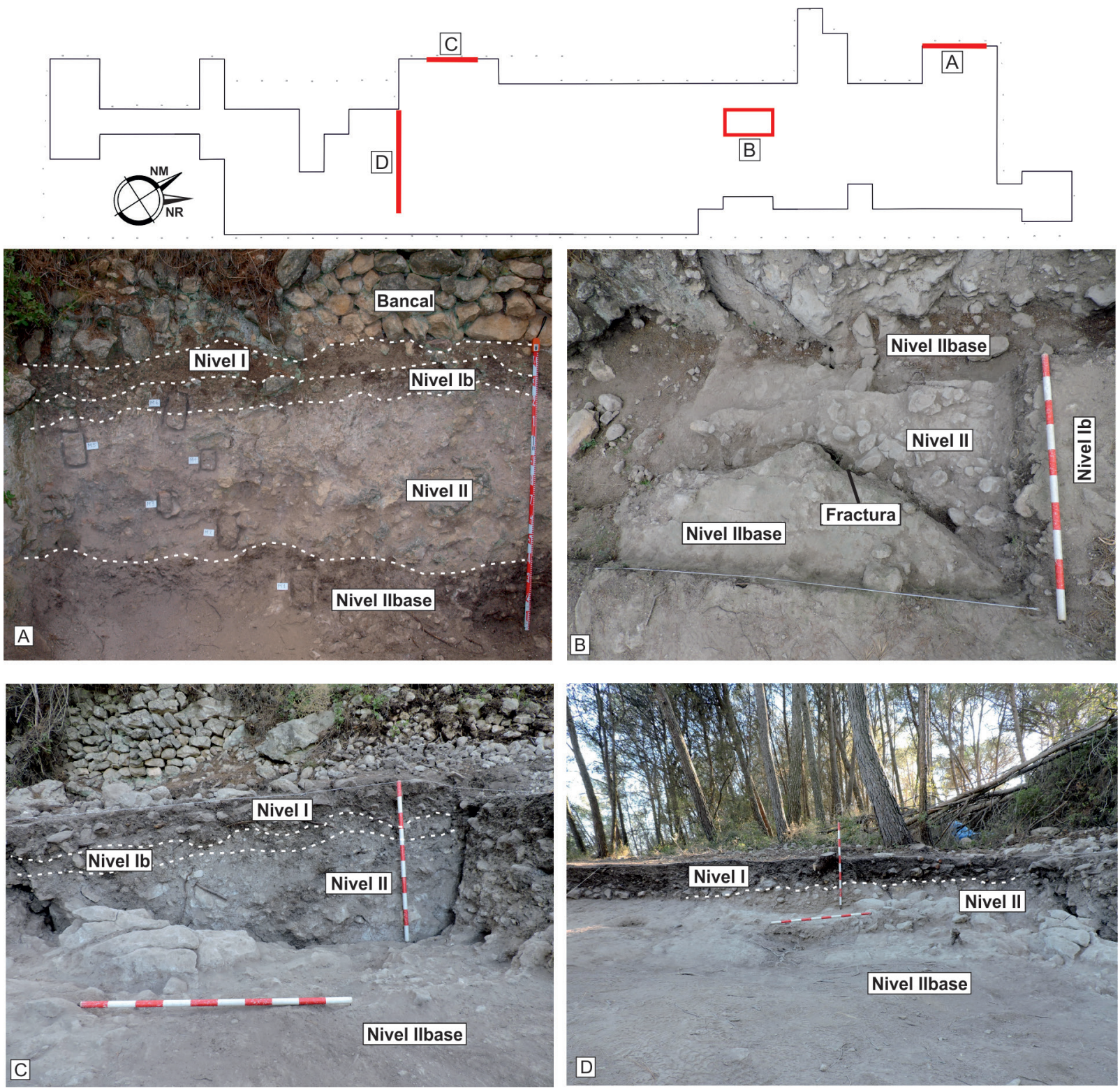

Fig. 3. Les Guixeres de Vilobí. Localización de las imágenes en el plano general de las excavaciones. A. corte N-S, cuadros M31-33; B. planta J-41/42, mostrando las fallas y el desnivel de los niveles arqueológicos; C. corte N-S, cuadros L-M/51-53; D. corte O-E, cuadros G-J 54/55 (autoría Mestres, Oms, Martínez-Grau, Laborda y Bergadà) (A, año 2018; B, año 2019; C, año 2016; D, año 2016). En color en la edición electrónica.

Nivel I. Potencia media de 10 a $20 \mathrm{~cm}$. Constituido por arcillas limosas de color marrón oscuro (10YR 4/2) muy orgánico con una estructura granular con cantos y algunos bloques de caliza de morfología subredondeada. Aparece material arqueológico. A medida que se profundiza disminuye el contenido orgánico, denominado $\mathrm{Ib}$.

Nivel II. Potencia media entre $60-120 \mathrm{~cm}$ según los sectores. Está formado por arcillas limosas de color marrón claro (10YR 6/3) con trazas de cementación que aumenta en los primeros $25 \mathrm{~cm}$ del nivel. Aparecen cantos y bloques de caliza de morfología subredondeada sin clasificar que aumentan a partir de $45-50 \mathrm{~cm}$ del nivel en el corte M31-33, junto con un incremento de la fracción limoarenosa en la matriz y de los restos carbonosos. También, se acentúan las trazas de alteración térmica en los cantos (fisuración y nódulos de óxidos de hierro). En este nivel se localizan los suelos de ocupación y estructuras que resultan difíciles de distinguir salvo que estén limitadas o rellenas por bloques o que perforen el propio nivel. 
El final de la secuencia arqueológica está representado por el Nivel II base con una potencia media vista de $19 \mathrm{~cm}$ de arcillas limosas. Es de color marrón oscuro (10YR 5/2) en el corte M31-33 con trazas de cementación que se acentúan en el sector H33-32 y le confieren un color muy claro (10YR 7/6). Se caracteriza, en general, por una disminución de la fracción detrítica gruesa en relación a la parte terminal del Nivel II. Sólo está alterado por algunas pequeñas intrusiones de material arqueológico clavado y por estructuras negativas (normalmente de la fase más antigua del yacimiento) (Figs. 3A y 3C). En su techo aparecen ciertos espacios que hemos denominado "ámbitos". formando aparentes suelos. Se definirán más adelante.

Los procesos que intervienen en la formación de la secuencia de Les Guixeres, aún en estudio, son heterogéneos, principalmente geogénicos (de tipo coluvial, erosivo, edáfico) y también antropogénicos como bloques y cantos termoalterados fruto de estructuras desmanteladas, rellenos extraídos de estructuras negativas, etc.

El desarrollo estratigráfico se da, con ciertas discontinuidades, en todo el yacimiento, sin que el registro arqueológico se corresponda necesariamente con la secuencia descrita. Además, no todas las fases culturales aparecen en todo el yacimiento y, cuando lo hacen, su intensidad varía de un sector a otro. Esto se debe a cuestiones tafonómicas (detalladas a continuación) y a la propia idiosincrasia de las ocupaciones. Por ejemplo, en el tramo sur del yacimiento, sólo la ocupación cardial tiene un desarrollo continuo. Las demás se detectan a partir de estructuras negativas $\mathrm{y}$, de manera puntual, por tramos reducidos de nivel arqueológico (p. ej., las líneas 55 o 59, Figs. 4D y 4E).

La lectura de las ocupaciones de la secuencia de Les Guixeres es compleja, ya que hay fracturas causantes del desplazamiento de ciertos niveles estratigráficos (Figs. 3B, 4A, 4B, 4C). Algunas en sentido longitudinal N-S se desarrollan entre las líneas J y K de todo el yacimiento, muy marcadas entre los metros 31 y 45 y más moderadas desde el metro 46 hasta el 66 (Figs. 2B, 3A, 3B, 3C). Ello ha comportado una clara conservación diferencial del depósito. Al oeste (líneas M, L y K, Figs. 4A, 4B y 4C) se conserva un registro de $c$. $120 \mathrm{~cm}$ de potencia con una larga secuencia neolítica. En cambio, al este (líneas F, G, H, I, y J) decrece (Figs. 4A, 4B y 4C) hasta menos de $25 \mathrm{~cm}$ en los cuadros más orientales ( $\mathrm{F}$ y $\mathrm{G})$. En esta zona se documenta la parte más antigua de la secuencia y estructuras negativas posteriores. Por el momento lo atribuimos a que las citadas fracturas han hundido una parte de la secuencia mientras que el lado oriental quedó expuesto a los trabajos agrarios y la erosión. Este desajuste estratigráfico también se puede observar entre el sector septentrio-
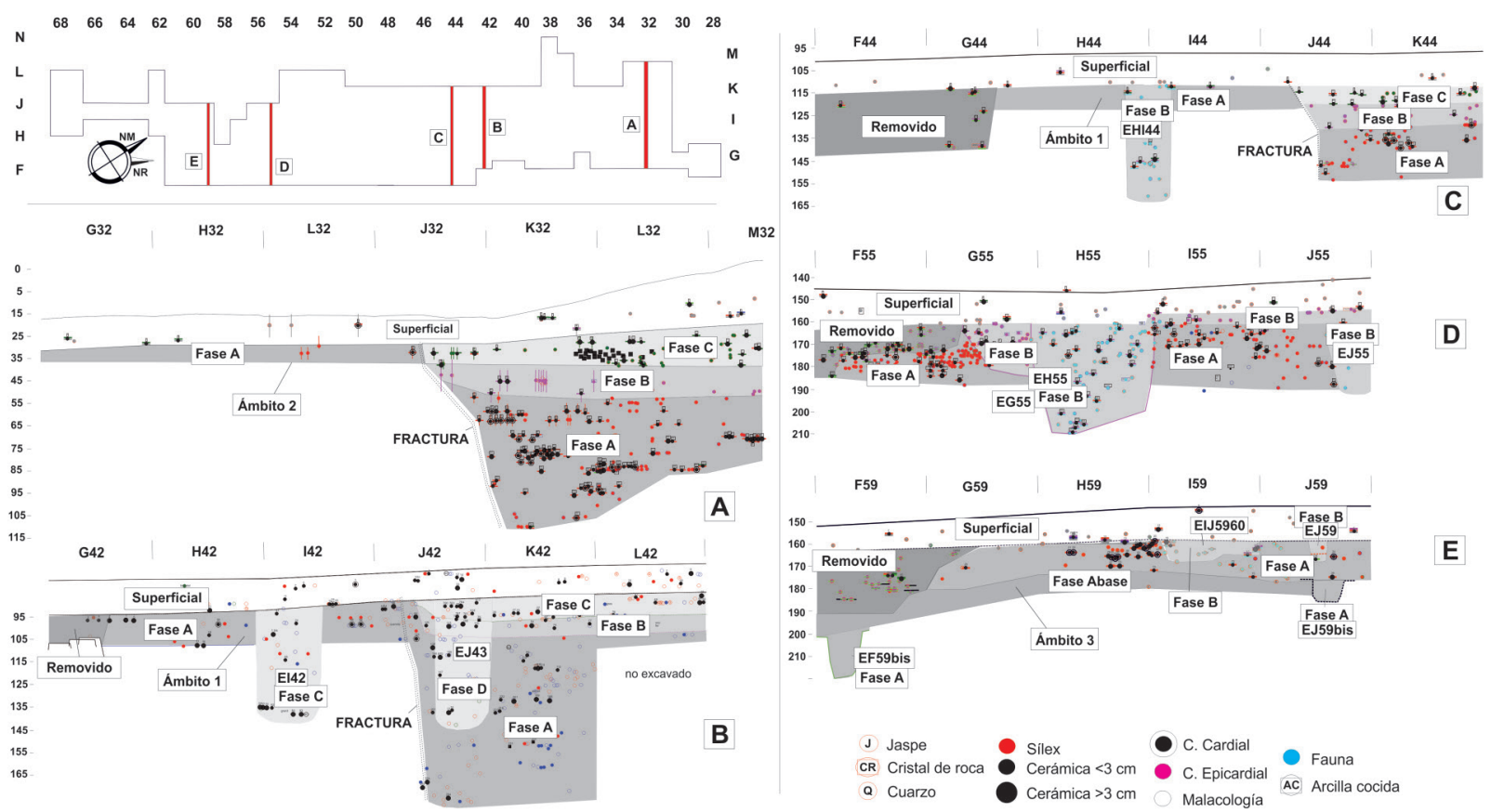

Fig. 4. Les Guixeres de Vilobí. Localización de 5 cortes estratigráficos Este-Oeste en el plano general de las excavaciones. Los cortes muestran la proyección de los materiales arqueológicos y de los niveles. La escala es doble en el caso de la potencia estratigráfica para facilitar su visibilidad (autoría Mestres, Oms, Martínez-Grau y Laborda). En color en la edición electrónica. 
nal del yacimiento (hasta la línea 44) y el meridional (hasta la línea 66). En el primero, más afectado por las fracturas, la estratigrafía es más completa y potente al hundirse parte del paquete sedimentario. En el segundo los niveles epicardiales, postcardiales y del Neolítico Final son inexistentes por su posible destrucción o muy escasa potencia. A veces, las evidencias provienen de las estructuras negativas que recortaron los niveles más antiguos (y profundos) (Figs. 4D y 4E).

\section{LAS FASES DE OCUPACIÓN Y LAS ESTRUCTURAS DE LES GUIXERES DE VILOBÍ}

El estudio estratigráfico y de los diferentes materiales arqueológicos ha permitido proponer un total de 4 ocupaciones. Las denominamos fases y no representan un continuum, sino amplios espacios cronológicos cuya cultura material es más o menos homogénea. Las estructuras "evidentes" fueron identificadas durante los trabajos de campo y las "latentes" a partir de las proyecciones de material. Las más habituales son los agujeros de poste, seguidas por las cubetas de tendencia abierta (a menudo estructuras de combustión) y, en menor medida, fosas-contenedor para la sujeción de vasos cerámicos (suelen aparecer grandes fragmentos en su interior) y silos. Además, en la Fase C y D, sendas estructuras negativas de gran tamaño podrían responder a estructuras habitacionales.

Los posibles suelos de ocupación y unidades habitacionales identificados por el momento son tres ámbitos específicos sin bloques termoalterados y material arqueológico más escaso (Fig. 5). Las posibles unidades habitacionales solo aparecen en la fase Cardial definidas por su morfología más o menos repetitiva, los remontajes cerámicos, líticos y ciertas concentraciones de material entre cada ámbito y su zona colindante. Se han denominado a partir del momento en que fueron identificados: Ámbito 1, Ámbito 2 y Ámbito 3.

\subsection{Fase $A$}

Corresponde a la ocupación del Neolítico Antiguo Cardial, la más antigua y potente del yacimiento. Está presente en toda su extensión. Tiene más de $80 \mathrm{~cm}$ de potencia en los sectores norte y central y solo $20 \mathrm{~cm}$ en el sector sur. Cuenta, al menos, con 3 episodios diferenciados según las dataciones radiocarbónicas disponibles, analizadas a continuación. Donde la potencia es mayor (Nivel II), esa distinción es también estratigráfica con dos capas como mínimo. Esta fase tiene los restos arqueozoológicos y carpológicos mejor preservados y el mayor número de evidencias líticas y óseas, restos malacológicos, etc. Se asocia con 21 estructuras negativas y 3 ámbitos que asociamos a zonas estrictas de hábitat (Fig. 5). Están rodeados por espacios muy ricos en material arqueológico de distinta naturaleza y bloques y clastos que, en general, están termoalterados:

Ámbito 1: se localiza en el sector central de Les Guixeres, entre F-J/41-49, en orientación norte. Tiene morfología elipsoidal, mide unos $8 \mathrm{~m}$ de largo, $5 \mathrm{~m}$ de ancho y su potencia es de 8-14 cm. Aparece en el techo del Nivel II base, muy cementado en la base, con un posible suelo compactado. La escasez de clastos y bloques y material arqueológico contrasta con la dinámica general del yacimiento. El ámbito está delimitado por el norte, el sur y el oeste por el Nivel II con abundancia de registro arqueológico y bloques y por el este por un afloramiento calcáreo recortado en parte. El material de mayor tamaño, sobre todo bloques y cerámica, decrece a medida que nos alejamos del interior del ámbito. A su alrededor se acumulan zonas de talla lítica y fauna a veces quemada. Hemos registrado remontajes cerámicos (directos e indirectos), entre su interior y su exterior más inmediato. En su interior, hay 3 agujeros de poste de gran diámetro y paredes rectas (Tab. 1), no alineados, lo que nos impide reconstruir el sistema de suspensión de una estructura aérea (Fig. 5).

Ámbito 2: se ha documentado de manera parcial en el sector norte, entre G-J/31-36. Su potencia es de $10 \mathrm{~cm}$. Comparte características edafosedimentarias con el Ámbito 1. Es un nivel yesoso sobre un suelo compactado del que se extrajo una muestra micromorfológica. Está limitado al sur y al oeste por potentes niveles arqueológicos con abundantes bloques y clastos. Los lados al este y al norte están sin excavar. Al interior hay poco material arqueológico y bloques. $\mathrm{Su}$ número y tamaño aumentan en el entorno exterior del ámbito. Existen remontajes cerámicos entre el interior y el exterior del mismo y entre fragmentos hallados al exterior. En su interior hay 3 agujeros de poste y probablemente 1 silo (Fig. 5, Tab. 1).

Ámbito 3: se halla en el límite sur del yacimiento, entre G-K/54-61. Orientado NE-SO, mide unos $8 \mathrm{~m}$ de longitud, $4 \mathrm{~m}$ de anchura y su potencia es de $15 \mathrm{~cm}$ con dos niveles con restos arqueológicos de dos fases de uso. Estos dos niveles se asientan, respectivamente, sobre suelos yesosos compactados. Se diferencia de los Ámbitos 1 y 2 por sus límites más difusos y el aumento de estructuras negativas de la misma fase o más recientes, lo que reduce su visibilidad en planta. Los tramos sin estructuras están mucho más limpios de materiales (apenas bloques y limitada potencia estratigráfica). Se conservan algunos tramos de alineamiento de bloques perimetrales en contacto con un afloramiento calcáreo de base, como en el Ámbito 1. Futuras campañas delimitarán mejor su extensión sobre todo al oeste. Nueve agujeros de poste, hallados en su interior o en su 
FASE A

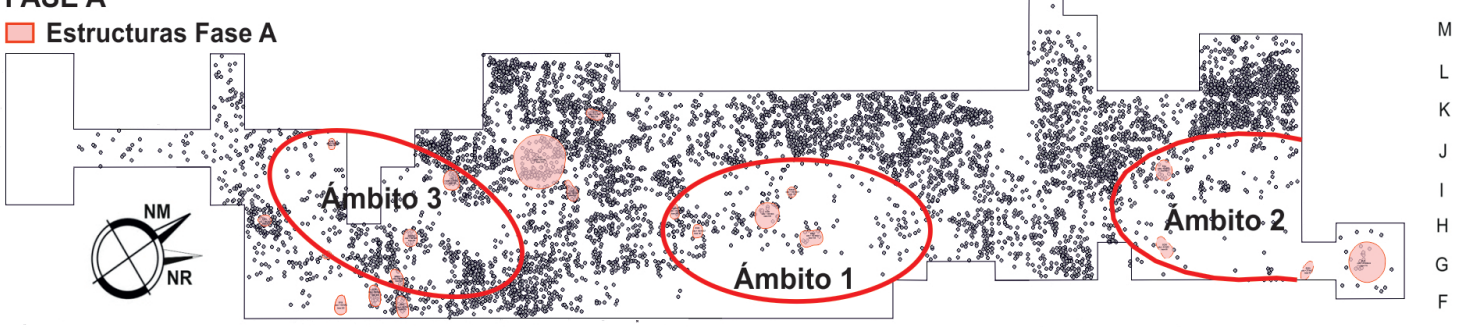

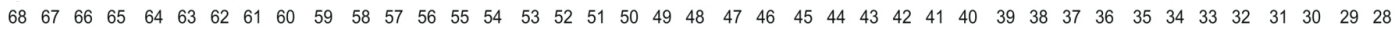
$\mathrm{N}$

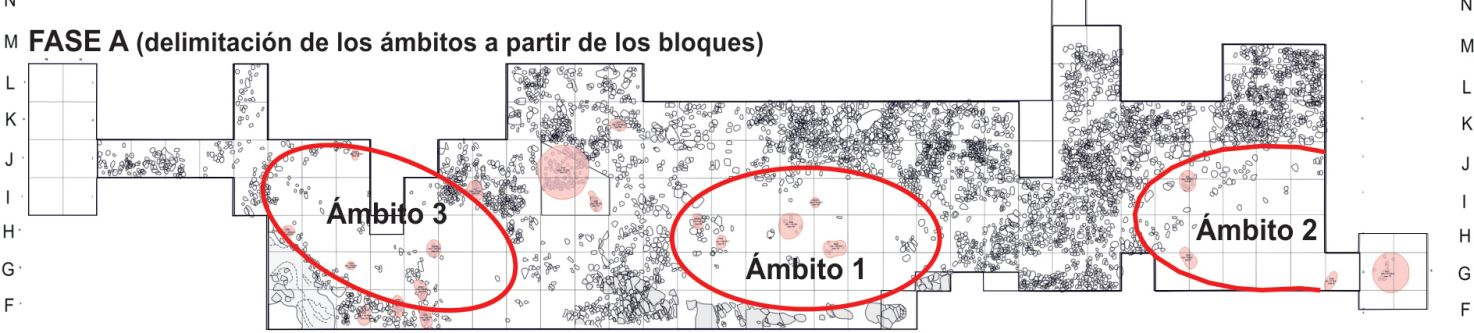

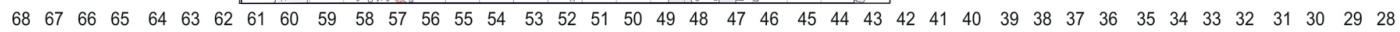

FASE B

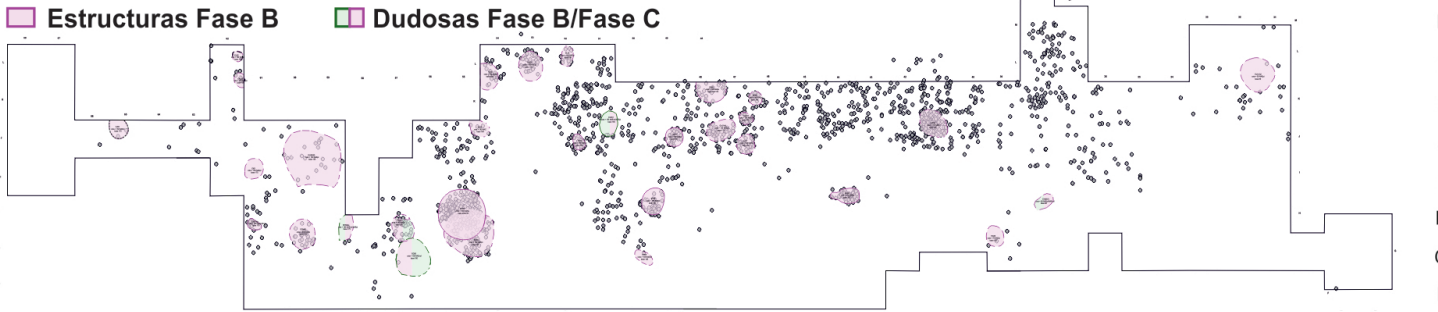

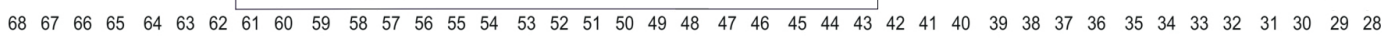

FASE C

$\square$ Estructuras Fase C $\square$ Dudosas Fase C/Fase B

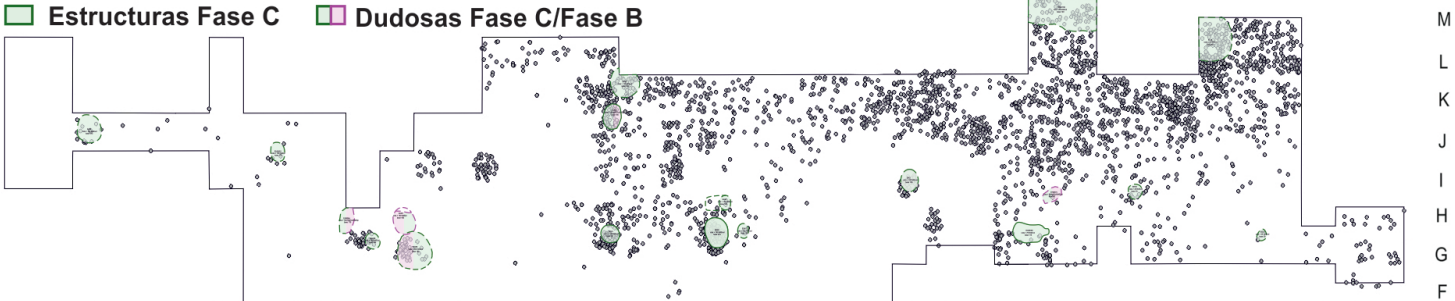

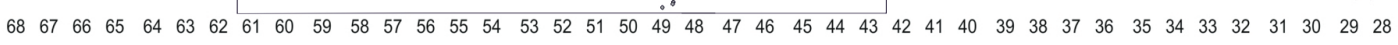

FASE D

$\square$ Estructuras Fase D

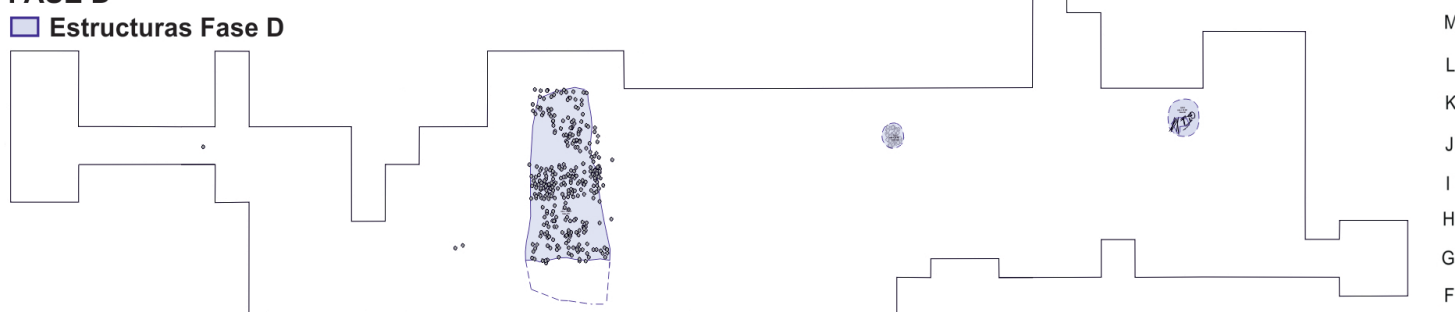

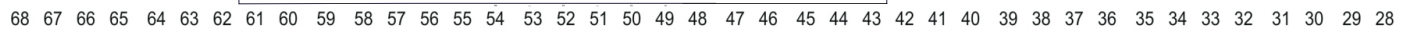

Fig. 5. Plantas por fase de las zonas de ocupación con material in situ y estructuras negativas de Les Guixeres. De la Fase A se presentan dos plantas con los ámbitos, una con los materiales arqueológicos in situ y otra donde se representa la presencia de bloques asociados a esta fase y con la cuadrícula del yacimiento para facilitar su comprensión espacial (autoría Mestres, Oms, Martínez-Grau y Laborda). En color en la edición electrónica.

Trab. Prehist., 78, N. ${ }^{\circ}$ 2, julio-diciembre 2021, pp. 257-276, ISSN: 0082-5638 
entorno inmediato, pertenecen a su misma fase. Sus diámetros se asemejan a los de los otros ámbitos (Fig. 5, Tab. 1).

Estructuras negativas ${ }^{1}$ (Fig. 5, Tab. 1): se asocian a esta fase un total de 21, la mayor parte catalogadas como agujeros de poste, excavadas en el sustrato del yacimiento. Sus dimensiones llegan hasta $60 \mathrm{~cm}$ de diámetro. Son de paredes verticales y base plana, con profundidades entre $15-30 \mathrm{~cm} \mathrm{y}$, en un caso, de más de $45 \mathrm{~cm}$. Suelen ser de planta circular o elipsoidal. Una elipsoidal tiene un lóbulo en su extremo, quizá para calzar el pilar principal con bloques o un poste oblicuo al principal. Es frecuente el hallazgo de pequeñas partículas de arcilla cocida en el techo e interior de las estructuras.
Además, hay una cubeta de combustión de $145 \mathrm{~cm}$ de diámetro máximo (EIJ53), una fosa-silo bien conservada (EG28/29) y una posible fosa-contenedor (Fig. 6 , EI55). Los restos de dos vasos hallados en su interior podrían haber servido como calzo de vasijas o de un poste.

\subsection{Fase $B$}

Esta ocupación, datada en el Neolítico Antiguo Epicardial, es menos intensa que la anterior (su potencia estratigráfica media es de $5-7 \mathrm{~cm}$ ) y se documenta especialmente en el lado oeste del yacimiento (Fig. 5, 36-55, H-L). Conserva menos restos de carbón y semillas que la Fase A.

\begin{tabular}{|c|c|c|c|c|c|c|}
\hline Fase & Estructura & Tipo & $\begin{array}{l}\text { Morfología } \\
\text { (planta) }\end{array}$ & $\begin{array}{l}\text { Diám max } \\
(\mathrm{cm})\end{array}$ & $\begin{array}{l}\text { Prof } \\
(\mathrm{cm})\end{array}$ & Función \\
\hline A & EG28/29 & evidente & circular & 105 & 85 & silo \\
\hline A & EG30 & evidente & elipsoidal & 60 & 15 & agujero de poste \\
\hline A & EG35 & evidente & elipsoidal & 60 & 35 & agujero de poste \\
\hline $\mathrm{A}$ & EI35 & evidente & circular & 55 & 25 & agujero de poste \\
\hline $\mathrm{A}$ & EI45/46 & evidente & circular & 30 & 20 & agujero de poste \\
\hline $\mathrm{A}$ & EH48 & evidente & subcircular & 35 & 15 & agujero de poste \\
\hline $\mathrm{A}$ & EH49bis & evidente & elipsoidal & $40($ ( 25) & 10 & agujero de poste \\
\hline $\mathrm{A}$ & EIJ53 & evidente & circular & 145 & 25 & cubeta combustión \\
\hline A & EK51 & latente & elipsoidal & $50(\mathrm{x} 30)$ & 35 & agujero de poste \\
\hline $\mathrm{A}$ & EI52 & evidente & $\begin{array}{l}\text { elipsoidal lobu- } \\
\text { lada }\end{array}$ & 45 (x 30 + lóbulo) & 45 & agujero de poste \\
\hline $\mathrm{A}$ & EH45 & evidente & elipsoidal & 60 & 35 & agujero de poste \\
\hline $\mathrm{A}$ & EH46 & evidente & circular & 60 & 15 & agujero de poste \\
\hline $\mathrm{A}$ & EH61 & evidente & circular & 40 & 15 & agujero de poste \\
\hline A & EG59* & evidente & circular & 30 & 10 & agujero de poste \\
\hline $\mathrm{A}$ & EF59 & evidente & elipsoidal & $50(\mathrm{x} 30)$ & 35 & agujero de poste \\
\hline A & EF58 & evidente & elipsoidal & $60($ (x 35) & 15 & agujero de poste \\
\hline $\mathrm{A}$ & EH57bis & evidente & circular & 40 & 5 & ¿agujero de poste? \\
\hline A & EFG57 & evidente & elipsoidal & $60(\mathrm{x} 35)$ & 25 & agujero de poste \\
\hline $\mathrm{A}$ & EF57 & evidente & elipsoidal & $60(\mathrm{x} 30)$ & 30 & agujero de poste \\
\hline A & EI55 & evidente & circular & 50 & 20 & $\begin{array}{l}\text { agujero de poste / fosa } \\
\text { contenedor }\end{array}$ \\
\hline A & EJ59bis & evidente & circular & 30 & 15 & agujero de poste \\
\hline
\end{tabular}

Tab. 1. Les Guixeres. Estructuras negativas de la ocupación de la Fase A. Lleva asterisco la atribuida a nivel estratigráfico (sin material asociado o poco significativo).

${ }^{1}$ Las estructuras se identifican con su letra inicial "E" y el cuadro o cuadros donde se localizan. Si hay más de una en un mismo cuadro, se añade "bis" a la segunda.
El nivel de ocupación (un palimpsesto homogéneo a nivel cronológico) está definido por niveles extensos, estratos aislados y treinta estructuras negativas (Tab. 2;

Trab. Prehist., 78, N. ${ }^{\circ}$ 2, julio-diciembre 2021, pp. 257-276, ISSN: 0082-5638

https://doi.org/10.3989/tp.2021.12275 
Fig. 5). La gran mayoría son "latentes", al estar excavadas en los niveles subyacentes de la Fase A. Hay 19 agujeros de poste con diámetros máximos entre 45-65 $\mathrm{cm}$ y una profundidad de unos $20-25 \mathrm{~cm}$ y hasta $40 \mathrm{~cm}$ en algún caso. Son de morfología circular o elipsoidal, con paredes rectas y fondos planos. EKL62 y EH49 contenían grandes fragmentos de cerámica, por lo que podrían también interpretarse como fosas-contenedor destinadas a la sujeción de vasos. Existen 8 cubetas de unos $100 \mathrm{~cm}$ de diámetro y una profundidad de unos $25 \mathrm{~cm}$, salvo dos de combustión (entre 130 y $140 \mathrm{~cm}$ de apertura y potencia de hasta $45 \mathrm{~cm}$ ). La superposición de dos de las estructuras indica un uso del espacio reiterativo y separado en el tiempo. La EH55 (Fig. 6) amortizó en parte la EG55 de similar funcionalidad.

\subsection{Fase $\mathrm{C}$}

Esta ocupación de Les Guixeres corresponde a la facies regional Molinot del Neolítico Postcardial (Mestres y Esteve 2016). Está bien representada en los sec- tores norte (metros 31 a 51) y sobre todo oeste (líneas I a L, Fig. 5). En el sector sur solo aparece en algunas estructuras negativas. Se define por estratos más o menos continuos y estructuras negativas. Los restos bioarqueológicos (antiguos) suelen ser pocos donde el Nivel Postcardial se inicia desde el nivel superficial (húmico), mientras que son algo más abundantes cuando se documenta en el Nivel II.

Las 20 estructuras negativas (Tab. 3; Fig. 5) son 7 recortes de tipo cubeta y 12 agujeros de poste. La mayoría son "latentes", detectadas durante la proyección de materiales y niveles. Completa el total una gran depresión, excavada solo en parte por entrar en el perfil. Tiene $65 \mathrm{~cm}$ de potencia y mide al menos 200 x 160 cm (EM37-38).

Las cubetas van de los 70 a los $130 \mathrm{~cm}$ de diámetro con profundidades de hasta $35 \mathrm{~cm}$ conservados. Los agujeros de poste son circulares (hasta $60 \mathrm{~cm}$ de diámetro y unos $30 \mathrm{~cm}$ de profundidad), elipsoidales (80 - $100 \mathrm{~cm}$ de diámetro máximo) o elipsoidales con lóbulo (de gran tamaño). Se documentó también el silo
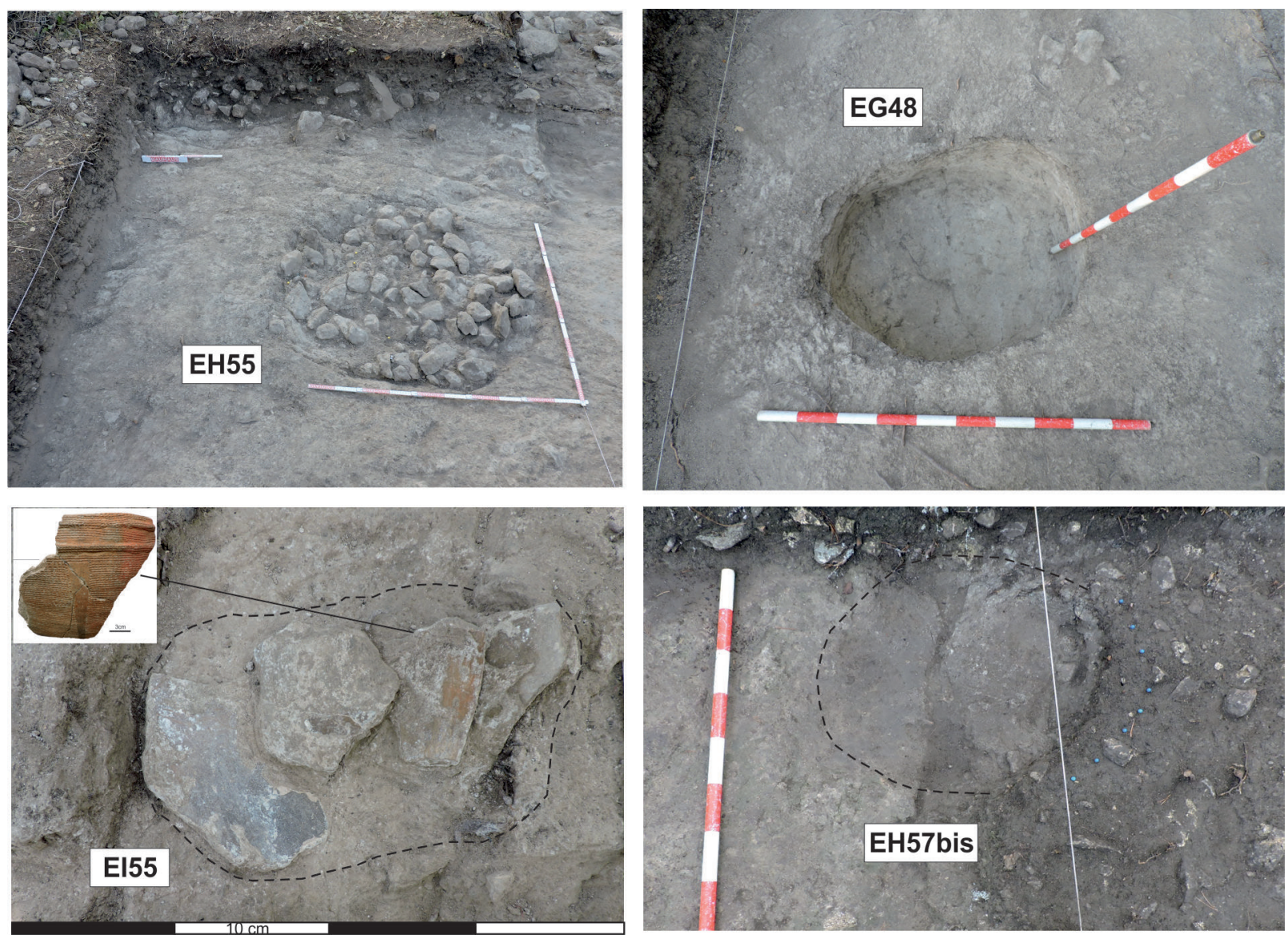

Fig. 6. Estructuras de Les Guixeres: EH55 cubeta de combustión (Fase B); EG48 silo (Fase C), EI55 fosa contenedor/agujero de poste; EH57bis probable agujero de poste (Fase A) (autoría Mestres, Oms, Martínez-Grau y Laborda). En color en la edición electrónica. 


\begin{tabular}{|c|c|c|c|c|c|c|}
\hline Fase & Estructura & Tipo & $\begin{array}{c}\text { Morfología } \\
\text { (planta) }\end{array}$ & $\begin{array}{c}\text { Diám max } \\
(\mathrm{cm})\end{array}$ & $\begin{array}{l}\text { Prof } \\
(\mathrm{cm})\end{array}$ & Función \\
\hline $\mathrm{B}$ & EK46 & latente & circular & 40 & 25 & agujero de poste \\
\hline B & EKJ47 & latente & circular & 40 & 25 & agujero de poste \\
\hline B & EKL62 & evidente & circular & 40 & 30 & agujero de poste \\
\hline $\mathrm{B}$ & EJ47 & latente & circular & 50 & 30 & agujero de poste \\
\hline $\mathrm{B}$ & EG39 & evidente & circular & 55 & 45 & agujero de poste \\
\hline $\mathrm{B}$ & EL62* & evidente & subcircular & 30 & 25 & agujero de poste \\
\hline $\mathrm{B}$ & EI61* & latente & circular & 50 & 15 & ¿agujero de poste? \\
\hline $\mathrm{B}$ & EL31/32 & latente & circular & 90 & 25 & cubeta \\
\hline $\mathrm{B}$ & EL53 & latente & subcircular & 80 & 30 & cubeta \\
\hline $\mathrm{B}$ & EH49 & latente & circular & $40(\mathrm{x} \mathrm{25)}$ & 25 & agujero de poste \\
\hline $\mathrm{B}$ & EJ49 & evidente & circular & 50 & 40 & agujero de poste \\
\hline $\mathrm{B}$ & EJK41 & latente & subcircular & 90 & 30 & agujero de poste / cubeta \\
\hline $\mathrm{B}$ & EJK47 & latente & circular & 40 & 25 & agujero de poste \\
\hline $\mathrm{B}$ & EK48 & latente & circular & 90 & 20 & cubeta \\
\hline $\mathrm{B}$ & EL52 & latente & elipsoidal & $60(\mathrm{x} 35)$ & 30 & agujero de poste \\
\hline B & EJ47/48 & evidente & elipsoidal & $85(x 50)$ & 30 & ¿agujero de poste / cubeta? \\
\hline $\mathrm{B}$ & EJ52 & latente & elipsoidal & 50 & 25 & agujero de poste \\
\hline $\mathrm{B}$ & EJ52bis & latente & elipsoidal & $60(\mathrm{x} 40)$ & 25 & agujero de poste \\
\hline $\mathrm{B}$ & EJ55* & latente & circular & 50 & 30 & ¿agujero de poste? \\
\hline $\mathrm{B}$ & EG50* & latente & elipsoidal & $60(\mathrm{x} 30)$ & 30 & agujero de poste \\
\hline $\mathrm{B}$ & EJ65 & latente & circular & 60 & 15 & agujero de poste \\
\hline $\mathrm{B}$ & EK52 & latente & subcircular & 80 & 15 & cubeta \\
\hline $\mathrm{B}$ & EH55 & evidente & circular & 140 & 45 & ¿cubeta combustión? \\
\hline $\mathrm{B}$ & EH38 & latente & elipsoidal & 60 & 20 & ¿agujero de poste? \\
\hline $\mathrm{B}$ & EH58bis* & latente & elipsoidal & $65(\mathrm{x} 40)$ & 15 & ¿agujero de poste? \\
\hline $\mathrm{B}$ & EH61bis* & latente & elipsoidal & $40(\mathrm{x} 25)$ & 15 & agujero de poste \\
\hline $\mathrm{B}$ & EHI44 & evidente & $\begin{array}{l}\text { elipsoidal lobu- } \\
\text { lada }\end{array}$ & $\begin{array}{c}60 \text { (x } 25+ \\
\text { lóbulo) }\end{array}$ & 55 & agujero de poste \\
\hline $\mathrm{B}$ & EGH60* & latente & circular & 80 & 20 & cubeta \\
\hline $\mathrm{B}$ & EG55 & latente & circular & 135 & 25 & ¿cubeta combustión? \\
\hline $\mathrm{B}$ & EL54 & latente & circular & 80 & 25 & cubeta \\
\hline
\end{tabular}

Tab. 2. Les Guixeres. Estructuras negativas de la Fase B. Llevan asterisco las atribuidas a nivel estratigráfico (sin material asociado o poco significativo).

EG48 de perfil globular, $80 \mathrm{~cm}$ de diámetro y $65 \mathrm{~cm}$ de profundidad (Fig. 6).

\subsection{Fase D}

Esta ocupación corresponde al Neolítico Final. Su desarrollo lateral muy reducido y la menor cantidad de materiales y estructuras sugieren una ocupación menos intensa (Fig. 5). Sus testimonios están dispersos por buena parte del yacimiento. El que sea la capa superficial nos impide reconocer si realmente fue una fase con ocupación más intensa no conservada.

Tres estructuras negativas (Tab. 4; Fig. 5) pertenecen a esta fase: un agujero de poste con paredes rectas y fondo aplanado; un silo y el fondo de una posible

Trab. Prehist., 78, N. ${ }^{\circ} 2$, julio-diciembre 2021, pp. 257-276, ISSN: 0082-5638

https://doi.org/10.3989/tp.2021.12275 


\begin{tabular}{|c|c|c|c|c|c|c|}
\hline Fase & Estructura & Tipo & Morfología (planta) & $\begin{array}{l}\text { Diám max } \\
\text { (cm) }\end{array}$ & $\begin{array}{l}\text { Prof } \\
(\mathrm{cm})\end{array}$ & Función \\
\hline $\mathrm{C}$ & EF8* & evidente & elipsoidal & $60(\mathrm{x} 20)$ & 10 & ¿agujero de poste? \\
\hline $\mathrm{C}$ & EF7* & evidente & circular & 30 & 10 & ¿agujero de poste? \\
\hline $\mathrm{C}$ & EG32 & evidente & circular & 35 & 10 & agujero de poste \\
\hline $\mathrm{C}$ & EG39/38 & evidente & elipsoidal lobulada & $60(\mathrm{x} 120)$ & 40 & agujero de poste \\
\hline $\mathrm{C}$ & EH35 & evidente & circular & 40 & 30 & agujero de poste \\
\hline $\mathrm{C}$ & EH47 & evidente & circular & 40 & 25 & agujero de poste \\
\hline $\mathrm{C}$ & EH57* & latente & subcircular & 60 & 20 & agujero de poste \\
\hline $\mathrm{C}$ & EIJ59/60* & latente & subcircular & 160 & 20 & cubeta \\
\hline $\mathrm{C}$ & EG47 & evidente & subcircular & 35 & 20 & agujero de poste \\
\hline $\mathrm{C}$ & EG51 & latente & circular & 50 & 30 & agujero de poste \\
\hline $\mathrm{C}$ & EK50 & latente & circular & 80 & 25 & cubeta \\
\hline $\mathrm{C}$ & EG48 & evidente & circular & 80 & 65 & silo \\
\hline $\mathrm{C}$ & EGH58* & latente & circular & 40 & 25 & ¿agujero de poste? \\
\hline $\mathrm{C}$ & EIJ60/61 & latente & subcircular & 50 & 15 & ¿agujero de poste? \\
\hline $\mathrm{C}$ & EG56* & latente & circular & 100 & 25 & cubeta \\
\hline $\mathrm{C}$ & EI42 & evidente & circular & 55 & 55 & agujero de poste \\
\hline $\mathrm{C}$ & EL33 & latente & circular & 130 & 30 & cubeta \\
\hline $\mathrm{C}$ & EJ66 & latente & circular & 75 & 15 & cubeta \\
\hline $\mathrm{C}$ & EJK51 & latente & subcircular & 60 & 30 & agujero de poste \\
\hline $\mathrm{C}$ & EM37/38 & latente & ¿subrectangular? & $>200(x>160)$ & 65 & $\begin{array}{l}\text { indefinible (entra en el } \\
\text { perfil) }\end{array}$ \\
\hline
\end{tabular}

Tab.3. Les Guixeres. Estructuras negativas de la Fase C. Llevan asterisco las atribuidas a nivel estratigráfico (sin material asociado o poco significativo).

\begin{tabular}{|c|c|c|c|c|c|c|}
\hline Fase & Estructura & Tipo & $\begin{array}{c}\text { Morfología } \\
\text { (planta) }\end{array}$ & $\begin{array}{c}\text { Diám max } \\
(\mathbf{c m})\end{array}$ & $\begin{array}{c}\text { Prof } \\
\text { (cm) }\end{array}$ & Función \\
\hline D & EK34 & latente & circular & 100 & 60 & silo con inhumación \\
\hline D & EJ43 & latente & circular & 60 & 55 & agujero poste \\
\hline D & EFK5253 & latente & $\begin{array}{c}\text { subrectangular/ } \\
\text { elipsoidal }\end{array}$ & $>450$ (x 200) & 15 & fondo estructura hábitat \\
\hline
\end{tabular}

Tab. 4. Les Guixeres Estructuras negativas de la Fase D.

estructura de hábitat. El silo fue amortizado con una inhumación primaria en decúbito lateral (adulto masculino, 25-35 años) que, a causa de una fractura sedimentaria, había perdido buena parte del cráneo y el brazo derecho completo. El material de su interior se asemeja más a un vertido de escombrera que a un ajuar. El citado posible fondo de un hábitat es de forma aproximadamente sub-rectangular, pero los trabajos agrarios han degradado su límite oriental.

\section{LAS DATACIONES RADIOCARBÓNICAS}

Hasta el momento se han obtenido 9 fechas radiocarbónicas: 5 de la fase A, 2 de la B, 1 de la C y 1 de la $\mathrm{D}$. Tres muestras sobre restos óseos (2 de la fase A y 1 de la B) carecieron de suficiente cantidad/calidad del colágeno para la datación (Tab. 5; Fig. 7).

Fase A: la muestra de la fecha OxA-26068 fue un M3 superior de Ovis/Capra hallado en el interior del 
Ámbito 1 (cuadro G49). El material para la fecha OxA26069, una primera falange de Ovis aries, procede del entorno inmediato del Ámbito 2 (cuadro K32). Beta486365 y Beta-486366 se obtuvieron del interior del Ámbito 3 (cuadro K54 y agujero de poste EI55) a partir de un fragmento de diáfisis de hueso largo (macromamífero indeterminado) y un M1-M2 superior izquierdo de Ovis/Capra respectivamente. Para el relleno basal y primer uso de este ámbito se ha obtenido la fecha Beta-574948 sobre una semilla doméstica (Hordeum vulgare) hallada en el cuadro J56.

Fase B: Beta-574949 corresponde a una semilla de herbácea Setaria sp. recuperada en la cubeta de combustión EH55. Para la fecha Beta-574950 se envió un M3 inferior de Ovis aries del Nivel Epicardial (cuadro K42).

Fase C: Beta-486363 se obtuvo de un fragmento de bellota, que formaba parte de una acumulación de más de 50, hallada en el cuadro K32.

Fase D: La muestra de Beta-486362 fue una segunda falange de la mano izquierda del individuo inhumado en el silo EK34 (Tab. 5).

\section{DATOS PRELIMINARES DE CULTURA MATERIAL Y RESTOS BIOARQUEOLÓGICOS}

La Fase A cuenta con 7029 registros: 2703 elementos líticos tallados (sílex, jaspe y cristal de roca), 45 macrolíticos (diversas litologías), 2219 cerámicos, 27 restos de arcilla cocida, 1771 de macrofauna y 185 de malacología marina. Otros materiales son muy minoritarios.

Se han contabilizado un mínimo de 286 vasos cerámicos (126 decorados). Los fragmentos decorados son 426. Se emplean técnicas impresas cardiales (oblicuo, oblicuo continuo, arrastrado, etc.) y cordones lisos o decorados. La industria lítica está ampliamente dominada por el sílex de procedencia regional (evaporítico y de origen marino). La otra litología característica es el cristal de roca, con 81 del total de 89 efectivos registrados en Les Guixeres. La cadena operativa está completa en ciertos espacios del yacimiento. En el amplio conjunto de retocados, destacan las muescas y denticulados (sobre lasca y lámina), las láminas con re-

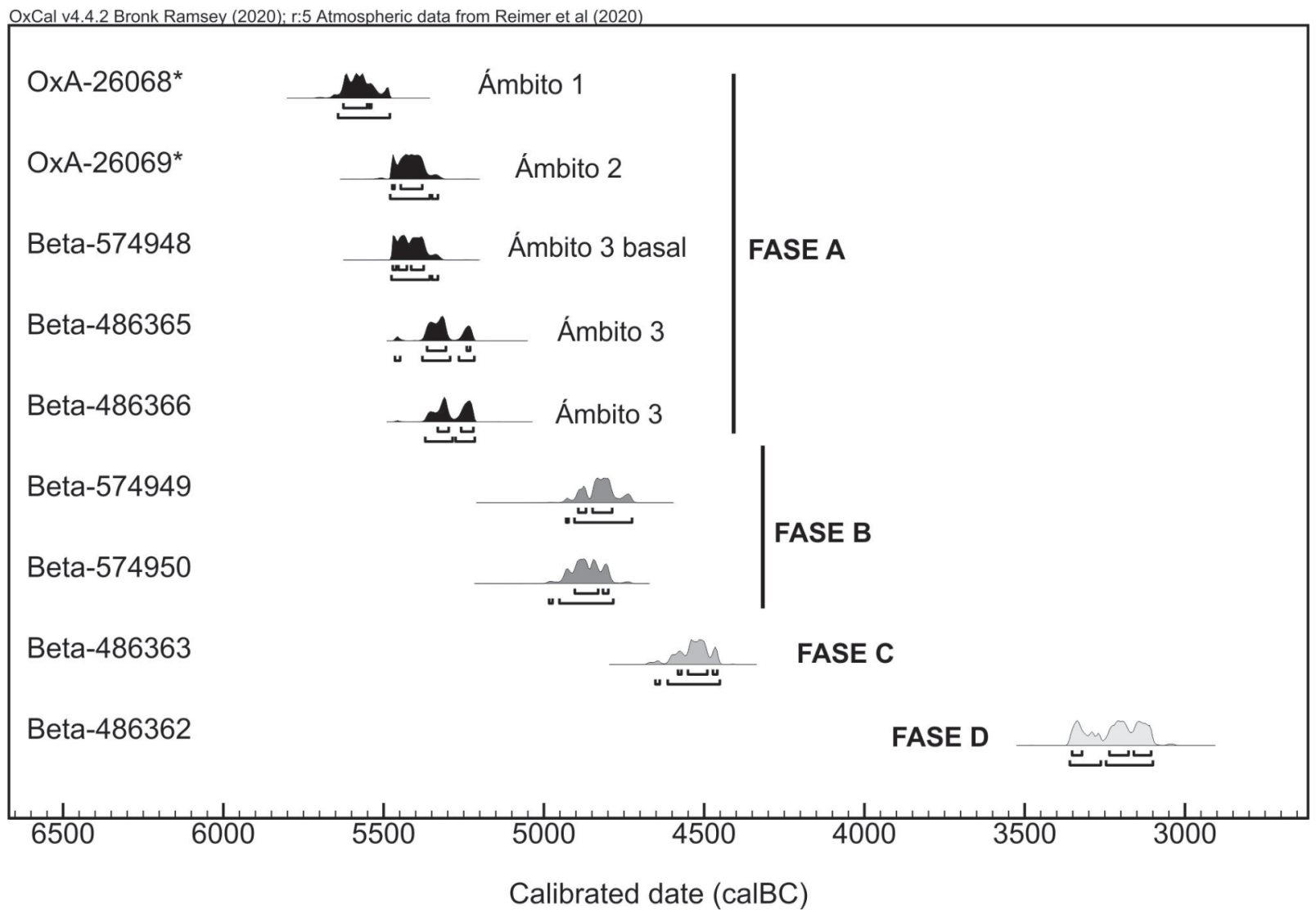

Fig. 7. Representación gráfica de las dataciones de Les Guixeres a $2 \sigma$ (OxCal 4.4., IntCal20, Reimer et al. 2020).

Trab. Prehist., 78, N. ${ }^{\circ}$ 2, julio-diciembre 2021, pp. 257-276, ISSN: 0082-5638 https://doi.org/10.3989/tp.2021.12275 


\begin{tabular}{|c|c|c|c|c|c|c|c|}
\hline Fase & Sigla & Material & D13C & Referencia & BP & SD & Cal BC 2s \\
\hline A & V-G49-39 & Ovis/Capra & -19.3 & OxA-26068* & 6655 & 45 & $5643-5481$ \\
\hline A & V-K32-87 & Ovis aries & -19.1 & OxA-26069* & 6458 & 38 & $5480-5331$ \\
\hline A & V-K38-84 & Ovis/Capra M3 inferior adulto & - & OxA & - & - & - \\
\hline A & V-G53-133 & Ovis/Capra frag diáfisis radio & - & OxA & - & - & - \\
\hline A & V18-J56 180-190 & Hordeum vulgare & -22.8 & Beta-574948 & 6440 & 30 & $5476-5331$ \\
\hline A & V16-K54-44 & Macromamífero indeterm & -18.3 & Beta-486365 & 6350 & 30 & $5465-5218$ \\
\hline A & V17-EI55-131 & Ovis/Capra & -20.1 & Beta-486366 & 6330 & 30 & $5371-5216$ \\
\hline B & V17-EH55-138 & Bos sp. escápula izquierda & - & Beta-486364 & - & - & - \\
\hline B & V-K42-46 & Ovis aries & -19.6 & Beta-574950 & 5980 & 30 & $4984-4784$ \\
\hline B & V17-EH55 z=175 & Setaria sp. & -23.3 & Beta-574949 & 5950 & 30 & $4931-4726$ \\
\hline C & V-K32 z=40 & Fragmento bellota & -23.9 & Beta-486363 & 5700 & 30 & $4653-4452$ \\
\hline D & V-EK34-197 & Hueso humano & -19.3 & Beta-486362 & 4520 & 30 & $3360-3101$ \\
\hline
\end{tabular}

Tab. 5. Dataciones radiocarbónicas de Les Guixeres, calibradas mediante el software OxCal 4.4 y la curva atmosférica IntCal'20 (Reimer et al. 2019). * ya publicadas (Oms et al. 2014); frag fragmento; indeterm indeterminado.

toques laterales $(\mathrm{NR}=141)$, los perforadores $(\mathrm{NR}=58)$ y los geométricos $(\mathrm{NR}=28,20$ trapecios, 6 triángulos y 2 segmentos). La decena de efectivos de la industria ósea están muy alterados y fragmentados. Predominan los soportes de economía, con tramos escasamente modificados y pulimento puntual para formar elementos apuntados y romos. Se les suman un posible mango de cuchara y un soporte fragmentado de extracción de anillos (Fig. 8).

La identificación de la fauna está dificultada por un alto grado de fracturación y de alteración provocada por procesos postdeposicionales. Aun así, en esta fase $\mathrm{y}$ en las posteriores se han reconocido evidencias tafonómicas del procesamiento antrópico de estos restos. Los caprinos domésticos son dominantes (c. $70 \%$ ). Los porcentajes de los bovinos domésticos y los suidos (salvajes/domésticos) varían entre el 15 y el $5 \%$ respectivamente. Los taxones salvajes (conejos, peces y aves) son anecdóticos. La malacología está diversificada: Glycimerys sp., Cerastoderma sp., Acanthocardia sp. y en menor medida Columbella rustica. Destacamos la documentación en torno al Ámbito 3 de toda la cadena de producción de cuentas de collar de concha: matrices pulidas y fragmentadas, cuentas rotas en el proceso de producción y cuentas completas ${ }^{2}$.

Los numerosos fragmentos de arcilla cocida tienen, a veces, improntas vegetales, a modo de torchis. Entre los 75 elementos macrolíticos hay azuelas y molinos

\footnotetext{
2 A. Emens. Arqueomalacologia marina d'un jaciment neolític antic al prelitoral. El cas de Les Guixeres de Vilobi (Sant Marti de Sarroca - Alt Penedès). Treball de final de Grau d'Arqueologia, Universitat de Barcelona, 2020, 60 pp.
}

(enteros y fragmentados), y numerosos cantos, en su mayoría con residuos de procesado de ocre. Los restos carpológicos (Hordeum vulgare, Triticum sp. y Cerealia) son escasos y están muy fragmentados por las alteraciones tafonómicas sufridas.

La Fase B tiene 2068 restos arqueológicos: 1259 elementos líticos (jaspe y sílex), 713 cerámicos, 190 de macrofauna, 78 malacológicos y 30 de arcilla cocida. El macroutillaje y otros materiales son muy minoritarios. Se han identificado 27 vasos cerámicos, 25 de ellos decorados. Este alto porcentaje de decoraciones está causado, en parte, por la presencia de impresiones o incisiones restringidas al labio. Los fragmentos decorados son 125. Las técnicas mayoritarias son las impresiones simples, con boquique, con gradina puntualmente, las incisiones/acanalados y los cordones impresos (Fig. 9). Las impresiones cardiales faltan por completo. La industria lítica emplea los mismos tipos de sílex de la Fase A y el jaspe. Disminuyen mucho los perforadores $(\mathrm{NR}=3)$ y los geométricos $(\mathrm{NR}=12,8$ trapecios y 4 segmentos) frente a las láminas con retoque lateral, las muescas y los denticulados (en total NR=76). Predominan los caprinos domésticos, seguidos por los bovinos $\mathrm{y}$, con carácter residual, los équidos. La mayoría de los taxones de malacofauna continúan siendo usadas, con novedades como Spondylus gaederopus y la disminución clara de Columbella rustica. El macroutillaje y la piedra pulida descienden bastante, pero hay todavía algunos fragmentos de molinos, cantos con ocre y parte de un brazalete de mármol.

La Fase C tiene 2234 registros: 959 son restos cerámicos, 803 de sílex, 194 de cuarzo, 102 de macrofauna y 47 de arcilla cocida. El macroutillaje, el ocre, 

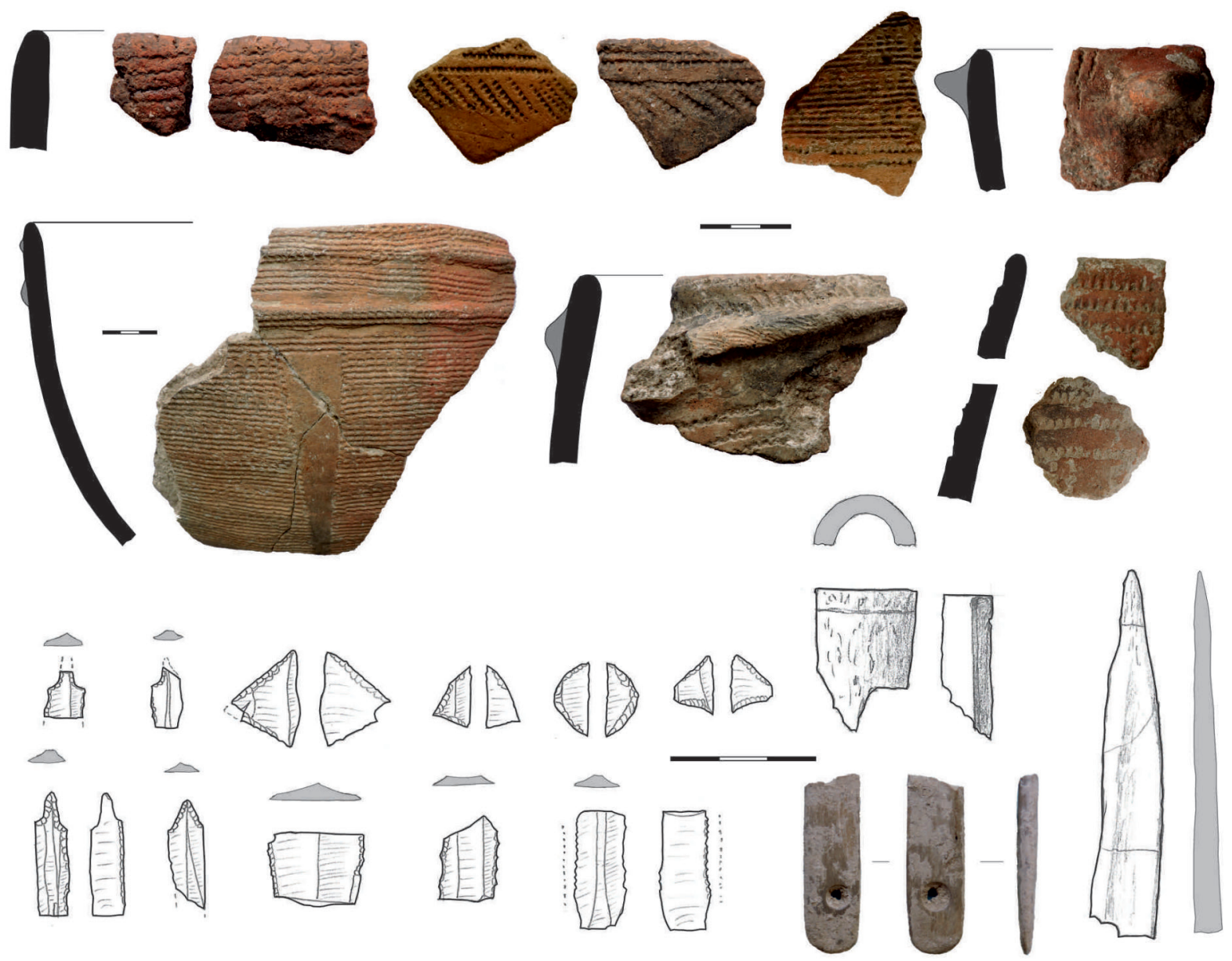

Fig. 8. Materiales cerámicos, líticos y óseos de la Fase A de Les Guixeres. Escala en cm (autoría Mestres, Oms, Martínez-Grau y Laborda). En color en la edición electrónica.

la calaíta, etc. son testimoniales. Hay un mínimo de 76 vasos cerámicos ( 21 con cordones y crestas, Fig. 9). De manera residual se usa el esgrafiado y la incisión. Los fragmentos decorados son 109. En este Neolítico Postcardial destaca el bajo número de efectivos peinados: 158 correspondientes a 12 vasos. Descienden bastante los elementos líticos de la cadena operativa y retocados (sobresalen las láminas no retocadas). Encontramos escasos taladros $(\mathrm{NR}=4)$ y geométricos $(\mathrm{NR}=2)$, frente a láminas con retoque lateral, muescas y denticulados $(\mathrm{NR}=54)$. Continúan los tipos de sílex mayoritarios en las fases previas, pero el jaspe y el cristal de roca desaparecen a favor de los artefactos en cuarzo que tienen cierta entidad. La fauna, poco representada (probablemente por motivos tafonómicos), repite el protagonismo de los caprinos domésticos, si bien los bóvidos ascienden (supera el $30 \%$ ). Es destacable el alto número de restos de torchis de esta Fase (aunque estos proceden casi en exclusiva del interior de la EG48), así como los restos de bellota (entorno del cuadro K32). Hay cierta continuidad en las plaquetas y cantos, pero disminuyen los molinos y otros útiles pulimentados.

La Fase D es la más pobre de la secuencia. Tiene 241 elementos: 72 cerámicos, 22 de sílex, 58 de macrofauna y 75 de la inhumación. Cuarzo, macroutillaje, etc. son muy escasos. Se han establecido un mínimo de 11 vasos cerámicos (1 decorado con cordones lisos y 1 con pastillas). Típicos de esta fase son dos vasos con carena baja suave y otro con lengüeta. En el sílex no hay evidencias de talla in situ. Entre los 12 retocados detectados, destacan una punta foliácea de retoque plano y un fragmento de gran lámina. Por primera vez dominan los restos de Bos taurus y los de caprinos domésticos apenas tienen protagonismo, en un conjunto general muy pequeño. El taxón Canis sp. es exclusivo de esta fase. 

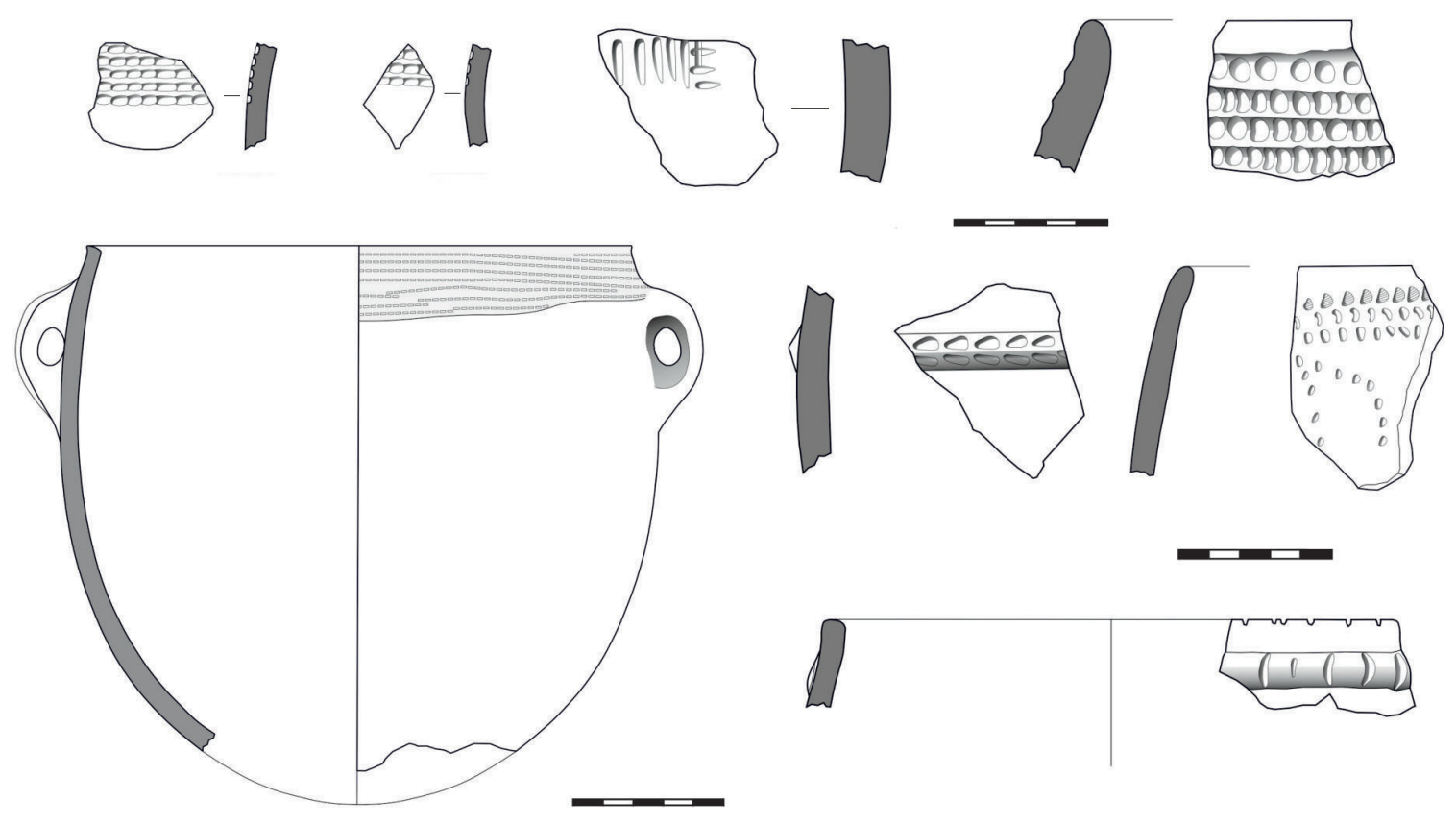

Fase B

Fase C
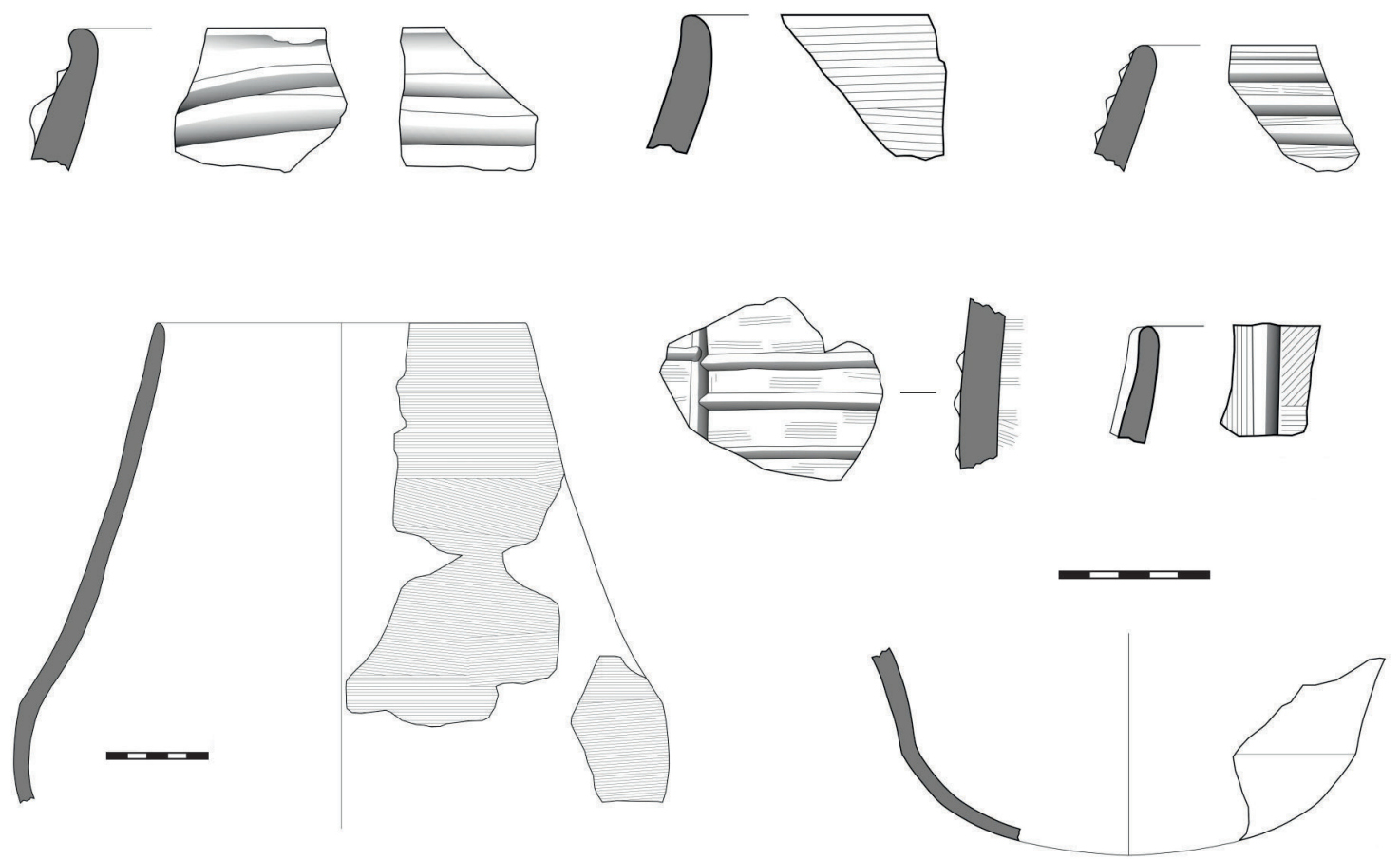

Fig. 9. Materiales cerámicos significativos de las Fases B y C de Les Guixeres. En los materiales de la Fase B se pueden observar impresiones de instrumento y codones impresos. En los materiales de la Fase $\mathrm{C}$ se pueden observar acabados peinados, crestas y cordones y un perfil cerámico carenado. Escala en cm (autoría a Mestres, Oms, Martínez-Grau y Laborda). 
Fuera de contexto se han recuperado tres fragmentos de cerámica campaniforme regional, pertenecientes a dos vasos distintos. No hemos podido detectar, por el momento, ningún nivel o estructura que se pueda datar en el Calcolítico o en el Bronce Antiguo en Les Guixeres.

\section{DISCUSIÓN Y CONCLUSIONES}

La complejidad estratigráfica de Les Guixeres se analiza en profundidad tras cada campaña para definir correctamente las fases cronoculturales. En este marco, las dataciones radiocarbónicas permiten relacionar los ámbitos documentados en el yacimiento. Los resultados del análisis $\chi^{2}\left(\chi^{2}\right.$-Test: $\mathrm{df}=3 \mathrm{~T}=43.165$-5 \% 7.8-) de las fechas disponibles para la Fase A distinguen tres momentos de utilización. La datación más antigua es la del Ámbito 1. Las del primer uso del Ámbito 3 son sincrónicas a la del Ámbito 2 y, según las fechas del segundo uso del Ámbito 3, su ocupación fue posterior al resto de las del Neolítico Cardial. Es decir, la cronología del Ámbito 1 estaría a caballo de la Fase 0-1 del Neolítico Antiguo del nordeste de la península ibérica y los Ámbitos 2 y 3 entrarían de lleno en la Fase 1 regional (Oms 2017).

Las dataciones de la Fase B se sitúan en una horquilla de 4983-4726 cal BC, propia de las manifestaciones epicardiales del litoral y prelitoral de la región (Martín et al. 2010; Oms et al. 2016). Este hecho contrasta con las dataciones del Epicardial de los territorios peninsulares del interior, donde las producciones cerámicas de las mismas características son anteriores, c. 5300-5000 cal BC (Rojo et al. 2018; Laborda 2019).

La única fecha de la ocupación Postcardial (Fase C), 4653-4452 cal BC, es insuficiente para determinar la horquilla completa de esta fase en el yacimiento. En la comarca catalana del Penedès, es una de las más antiguas para el Neolítico Postcardial Molinot, sólo comparable con otras del nivel $11 \mathrm{~b}$ y 12 de la Cova de Can Sadurní (Edo et al. 2019: 309). La producción de Les Guixeres apunta a un índice bajo de cerámicas peinadas (a veces decoradas con crestas) en favor de las lisas y decoradas mediante cordones y nervaduras. Este rasgo diferencia este conjunto de la mayoría de las colecciones regionales del Postcardial Pleno, entre $c$. 4400-3900 cal BC, donde las cerámicas peinadas con o sin decoración dominan claramente (Mestres y Esteve 2016). Por tanto, la datación disponible y la producción cerámica del yacimiento parecen representativas de un Postcardial Antiguo, con una posible filiación con las producciones epicardiales evolucionadas.

La fecha de la Fase D, obtenida de una inhumación primaria en el silo EK34, concreta la cronología a fines del IV milenio (3360-3101 cal BC), durante las fases iniciales del Neolítico Final. En esta estructura y en el resto de las ocupaciones de esta fase del yacimiento, la presencia de cordones lisos y pastillas repujadas supondría ciertas similitudes con el horizonte Veraza. En el Penedès hay otros conjuntos similares, sobre todo en los campos de silos de Mas d'en Boixos, Cinc Ponts y La Serreta (todos en el término de Vilafranca del Penedès). En las numerosas cuevas sepulcrales de la zona durante el IV-III milenio cal BC, los indicadores Veraza o sus paralelos Trèilles y Ferrières son residuales salvo en la Cova de la Font del Molinot (Pontons), la Esquerda de les Roques del Pany (Torrelles de Foix) y la Cova de Batllevell (Pontons) (Mestres y Esteve 2016).

El poblado de Les Guixeres, por sus características, representa uno de los primeros enclaves neolíticos documentados en la península ibérica. Desde c. 5600 cal BC, se sucedieron ocupaciones durante el Neolítico Cardial, el Neolítico Antiguo Epicardial, Neolítico Postcardial y ya de manera residual, durante el Neolítico Final. Por la alta fragmentación y dispersión de las estructuras y materiales en las fases A, B y C proponemos que estas ocupaciones hayan sido intensas, reiteradas y continuadas en el tiempo, lo que, como veremos, no es habitual en otros asentamientos.

Los campos de silos son el otro tipo de ocupación al aire libre más común en el Neolítico peninsular con una fuerte y amplia implantación desde su inicio. No parecen relacionarse con asentamientos de carácter habitacional intenso o estable, dado que su asociación con agujeros de poste y/o estructuras de combustión es muy esporádica, exista o no un elevado arrasamiento moderno (Mestres y Esteve 2016; Oms y Martín 2018). En las primeras fases neolíticas del NE peninsular, el número de silos es bajo por yacimiento $(<5)$, salvo en la Font del Ros (Pallarés et al. 1997) y Sant Pau del Camp (Gómez y Molist 2017). Este panorama cambia a partir del Neolítico Postcardial. Entonces, su número aumenta exponencialmente. Por ejemplo, en el territorio inmediato a Les Guixeres hay más de 200 silos de esta cronología (Mestres y Esteve 2016). En la meseta aparecen desde el Neolítico Inicial en una cantidad considerable (Rojo et al. 2008), pero en otros territorios peninsulares, no lo hacen hasta el Epicardial y sobre todo el Postcardial (Torregrosa et al. 2011), con un claro auge a partir del Neolítico Final y Calcolítico (Bernabéu et al. 2006; Pérez-Jordá et al. 2011; Prats et al. 2020).

Al margen de los silos, la tipología de cabañas y unidades habitacionales es muy diversa desde el Neolítico Inicial. En el ámbito mediterráneo central y occidental los agujeros de poste definen sistemas de sostenimiento, perimetrales e internos, de hábitats de morfología cuadrangular y subcuadrangular. Para ello

Trab. Prehist., 78, N. ${ }^{\circ}$ 2, julio-diciembre 2021, pp. 257-276, ISSN: 0082-5638

https://doi.org/10.3989/tp.2021.12275 
se usa el torchis, la madera y sólo esporádicamente la piedra (Guilaine 2016).

Ámbitos parecidos a los de Les Guixeres (espacios con poco material y limpios de bloques rodeados de desechos arqueológicos) también han sido interpretados como cabañas en otros territorios cardiales y epicardiales relativamente cercanos, como el sur de Francia, Valencia y parte de Aragón. Uno de los casos más relevantes es Baratin (Couthezon) (Sénépart 2000, 2003). Presenta al menos tres momentos de ocupación dentro del Neolítico Cardial Pleno (c. 53005100 cal BC) con muy diversas estructuras: cubetas de combustión, espacios circulares empedrados de unos $15 \mathrm{~m}^{2}$, agujeros de poste con diámetro cercano a los $15 \mathrm{~cm}$ y dos posibles ámbitos habitacionales absidiales (Sénépart 2009). Ambos son algo mayores (40-50 $\mathrm{m}^{2}$ ) que los de Les Guixeres, estando delimitados por bloques y con modificaciones del substrato. Como en Les Guixeres, los remontajes de cerámica e industria lítica demostrarían cierta sincronía entre los ámbitos y los niveles colindantes. El asentamiento al aire libre de Lalo (Espeluche) sería otro ejemplo. En su fase IV (c. 5270-5000 cal BC) se documentaron dos cabañas formadas a partir de agujeros de poste. La mejor conservada tendría una morfología elipsoidal y aproximadamente $82,5 \mathrm{~m}^{2}$ (unos $11 \mathrm{~m}$ de largo por $7,5 \mathrm{~m}$ de ancho) (Beeching 2009; Gernigon 2016). En Peiro Signado (Portiragnes), c. 5800-5600 cal BC, la cabaña está definida por 9 agujeros de poste de $20-30 \mathrm{~cm}$ de diámetro, equidistantes unos $170 \mathrm{~cm}$, que forman un espacio elipsoidal de $8 \mathrm{~m}$ de largo por 5,5 $\mathrm{m}$ de ancho. Un conjunto de fosas situadas al oeste y sur de esta estructura son interpretadas como espacios de extracción de arcillas (Briois y Manen 2009).

En el nordeste de la península ibérica La Draga (Banyoles, c. 5300-5000 cal BC) es un ejemplo de primer orden de la arquitectura habitacional del Neolítico Antiguo Cardial (Mestres y Tarrús 2009) y, a la vez, muy específico, por su situación en el borde de un lago. En el suelo fangoso se levantan cabañas probablemente cuadrangulares (Mestres y Tarrús 2009; Barceló et al. 2019), acompañadas por estructuras empedradas y numerosos agujeros de poste, que indican una articulación compleja del espacio en 200-300 años de ocupación (Bosch et al. 2011). En Sant Pau del Camp (Barcelona), los 9 silos de la fase cardial se asocian con una serie de "tallas" (¿niveles?) con materiales sincrónicos y un centenar de agujeros de poste (Gómez y Molist 2017). En la Font del Ros (Berga) se documentó un sector con silos y otro, algo apartado, con un nivel de ocupación del Neolítico Antiguo, al que se asocian tres agujeros de poste (Rodà et al. 2019). En Can Xammar (Mataró) se excavaron dos fondos de cabaña con agujeros de poste internos y numerosos torchis y un silo (Pou et al. 2005).
En Alicante, en la fase más antigua de Mas d’Is se ha hallado la "Casa 1" compuesta por 12 agujeros de poste y otros más a su alrededor, cubetas de combustión y el "Foso 1" (Bernabéu et al. 2003; Bernabéu et al. 2012). El asentamiento de Benámer (Muro d'Alcoi), presentaba en su Fase II (Neolítico Cardial) cubetas de combustión de planta circular con $80-130 \mathrm{~cm}$ de diámetro y escasa potencia. No aparecieron agujeros de poste ni otros sistemas de sujeción aérea (Torregrosa et al. 2011: 88).

Las ocupaciones de las Fase B y C de Les Guixeres carecen de unidades habitacionales reconocibles, pero sus niveles arqueológicos y numerosas estructuras negativas indican una notable estabilidad y construcción de estructuras aéreas. El yacimiento epicardial de Mas de Vignoles X (Nimes) (c. 5100-4900 cal BC) sigue los parámetros de la fase A de Les Guixeres: ámbitos con poco material y limitados por bloques, rodeados de espacios con desechos arqueológicos, resultado de la limpieza ocasional del interior de los ámbitos, y de zonas de actividad (Perrin et al. 2014). Las características de la Plansallosa son también similares. Tiene dos ocupaciones (PSL-1 y PSL-2), datadas entre 5200-4800 cal BC, entre el Cardial Final y el Epicardial (Bosch et al. 1998) con cubetas de combustión, agujeros de poste y fosas. Según la documentación disponible podría haber algunas estructuras positivas de morfología celular para la fase más antigua $(210 \times 170 \mathrm{~cm}$ en planta) y elipsoidal para la fase reciente $(500 \times 280 \mathrm{~cm}$ en planta). En el Tossal de les Basses (Alicante) solo se ha documentado un fondo de cabaña de la primera fase de ocupación de unos $5 \mathrm{~m}$ de largo (c. Epicardial) (Rosser y Soler 2016). En Los Limoneros (Elche), se excavó un nivel arqueológico asociado a 18 silos y cubetas y 2 fosos (García Atiénzar et al. 2020). El asentamiento de Alonso Norte (Alcañiz) de una naturaleza similar a Les Guixeres, presenta un nivel de ocupación asociado a una cubeta de combustión y diversos agujeros de poste sin alineación determinable (Laborda et al. 2017).

Entre los yacimientos postcardiales (Fase C de Les Guixeres) destacan la E48 de La Serreta y la E24 de Mas Pujó en la misma comarca del Penedès, donde hay diferentes tipos de fondo de cabaña, uno cuadrangular con agujeros de poste y rasas y otro elipsoidal (Esteve et al. 2012; Oms y Martín 2018). Els Vilars de Tous (Igualada) también tiene una estructura de morfología elipsoidal. Tiene unos $10 \mathrm{~m}^{2}$ de extensión y un hogar en su interior (Clop et al. 2005). Ca l'Estrada II (Canovelles) destaca por sus dos estructuras empedradas con cantos de 3,5 m de diámetro publicadas como "cabañas con solera de piedras" (Roig et al. 2020: 223). A su alrededor hay cuatro cubetas de combustión y un paleocanal relleno de desechos arqueológicos. También cabría en esta fase la ocupación más antigua de Ca n'Isach (Palau Saverdera). Conserva una pequeña 
e incompleta cabaña cuadrangular de un mínimo de 8 $\mathrm{m}^{2}$ (EH-7) y un conjunto de estructuras asociadas, sobre todo cubetas de combustión (Tarrús 2017: 40). En territorio valenciano es especialmente relevante la fase II del Tossal de les Basses al menos con 5 fondos de cabaña y 3 fosos de drenaje, así como numerosas estructuras empedradas (Rosser y Soler 2016). En Benámer se halló un nivel húmico con materiales postcardiales y algunas agrupaciones de cantos. De esta misma fase se excavó una gran concentración de estructuras de tipo silo en otro sector del yacimiento (Torregrosa et al. 2011).

En el episodio del Neolítico Final de Les Guixeres aparecen de nuevo silos y cubetas. Esta dinámica es similar a otros yacimientos del Penedès (Mestres y Esteve 2016), donde encontramos 67 estructuras negativas entre silos, cubetas, agujeros de poste y hornos. En cambio, la inhumación en el silo EK34 supone un hito inédito en esta región, dado que coincide con una fase de auténtica explosión de inhumaciones colectivas en cuevas y abrigos (Mestres y Esteve 2016; Cebrià et al. 2017; Oms et al. 2018). Proponemos que sea una inhumación oportunista por la ausencia de ajuar y su localización al aire libre. La estructura habitacional de morfología cercana a la rectangular no es habitual en el Penedès. Sin embargo, podemos encontrar algunas morfologías similares (elipsoidal, cuadrangular o circular) en probables fondos de cabaña de Can Vinyalets II (Santa Perpètua de Mogoda) o Camp del Rector (Jorba) (Font 2006). En otras regiones más o menos próximas, durante el Neolítico Final y el Calcolítico se dan asentamientos mayores, con fuertes concentraciones de silos en Niuet y les Jovades, en Valencia (Bernabéu 1993). En Boussargues y Les Vautes, en el sur de Francia, es habitual construir con piedra los primeros poblados de espacio cerrado (Guilaine y Escallon 2004; Coularou et al. 2008).

En conclusión, el yacimiento de Les Guixeres presenta una compleja sucesión estratigráfica al aire libre poco común en otros territorios durante el Neolítico, que supera la diacronía habitual de los campos de silos y otros hábitats complejos al aire libre. En este contexto, es difícil determinar la duración de cada episodio y de cada estructura habitacional. Los estudios geoarqueológicos y micromorfológicos en curso ayudarán a determinar los suelos de hábitat en las diferentes fases y a conocer la formación del depósito arqueológico y de los ámbitos hasta ahora registrado.

En resumen, la ocupación más antigua de Les Guixeres es la mejor caracterizada. A ella se asocian tres ámbitos vinculados con el hábitat y distintas estructuras negativas, así como un potente paquete estratigráfico asociado. A tenor de las dataciones disponibles y del análisis $\chi^{2}$, dos ámbitos fueron ocupados durante un mismo periodo y el resto en momentos distintos, apuntando a una alta intensidad en la ocupación del yacimiento durante la Fase A. Sin embargo, no es descartable que el aumento de dataciones de la fase cardial difumine, de una manera o de otra, esta primera apreciación ocupacional. El tipo de hábitat que se da durante el Neolítico Cardial sugiere un constante mecanismo de ocupación/abandono tanto de este yacimiento, como de otros parecidos. Esto sería más acusado si cabe en las cuevas y abrigos del entorno. Por eso, habiendo intervenido en $c .10 \%$ del yacimiento, no podemos saber el número total de estas unidades habitacionales, su respectiva duración, ni cuántas pudieron ser ocupadas de manera sincrónica. La menor intensidad aparente del resto de las ocupaciones puede deberse a la erosión tanto natural como provocada por las labores agrícolas modernas. Los futuros trabajos arqueológicos, el cuidadoso proceso de proyecciones de los artefactos y las nuevas dataciones radiocarbónicas de elementos representativos en localizaciones certeras, estarán encaminados a solucionar estas limitaciones.

\section{AGRADECIMIENTOS}

El ayuntamiento de Sant Martí Sarroca, Josep Pané, Jordi Farré (Vinseum) y todos y todas las estudiantes que han participado en los trabajos de campo, nos han prestado una colaboración total. Los dos revisores o revisoras han mejorado la calidad del manuscrito con su corrección del texto y el apunte de mejoras.

\section{BIBLIOGRAFÍA}

Baldellou, V. y Mestres, J. 1981: "Les Guixeres de Vilobí, hàbitat del Neolític Antic a l'aire lliure". El Neolític a Catalunya. Taula rodona de Montserrat 1980): 69-74. Publicacions de 1'Abadia de Montserrat. Montserrat.

Barceló, J. A.; Calvano, M.; Campana, I.; Piqué, R.; Palomo, A. y LópezBultó, O. 2019: "Rebuilding the past: 3D Reconstruction and BIM Analysis of a Neolithic House at La Draga (Girona, Spain)". En H. Kremers (ed.): Digital Cultural Heritage. Springer Nature Switzerland. Cham: 157-168.

Beeching, A. 2009: "Les maisons ovales du Néolithique ancien de Lalo à Espeluche (Drôme)". En A. Beeching e I. Sénépart I. (eds.): De la maison au village. L'habitat néolithique dans le Sud de la France et le Nord-Ouest méditerranéen (Marseille 2003). Mémoire Société préhistorique française 48. Paris: 39-48.

Beeching A. y Sénépart I. (eds.) 2009: De la maison au village. L'habitat néolithique dans le Sud de la France et le Nord-Ouest méditerranéen (Marseille 2003). Mémoire Société préhistorique française 48. Paris.

Bernabeu, J. (ed.) 1993: "El III ${ }^{\mathrm{er}}$ milenio a.C. en el País Valenciano. Los poblados de Jovades (Cocentaina, Alacant) y Arenal de la Costa (Ontinyent, Valencia)". Saguntum-PLAV 26: 9-179.

Bernabéu, J.; Molina, L1.; Díez, A. y Orozco, T. 2006: "Inequalities and power. Three millennia of Prehistory in Mediterranean Spain (56002000 cal BC)". En P. Díaz-del-Río y L. García Sanjuán (eds.): Social Inequality in Iberian Late Prehistory. British Archaeological Reports, International series 1525, BAR Publishing. Oxford: 97-116. 
Bernabéu, J.; Orozco, T. y Díez-Castillo, A. 2012: "Mas d’Is y las construcciones con fosos del VI al III milenio cal a.C.". MARQ. Arqueología y Museos 5: 53-72.

Bernabeu, J.; Orozco, T.; Díez, A.; Gómez, M. y Molina, F. J. 2003: “Mas d'Is (Penàguila, Alicante): aldeas y recintos monumentales del Neolítico Inicial en el valle del Serpis". Trabajos de Prehistoria 60 (2): 39-59. https://doi.org/10.3989/tp.2003.v60.i2.80

Bosch, À.; Buxó, R.; Palomo, A.; Buch, M.; Mateu, J.; Tabernero, E. y Casadevall, J. 1998: El poblat neolític de Plansallosa. L'explotació del territorio dels primers agricultors-ramaders de l'Alta Garrotxa. Publicacions Eventuals d'Arqueologia de la Garrotxa 5. Olot.

Bosch, À.; Chinchilla, J. y Tarrús, J. 2000: El poblat lacustre neolític de la Draga. Excavacions de 1990 a 1998. Monografies del Centre d'Arqueologia Subaquàtica de Catalunya 3. Girona.

Bosch, À., Chinchilla, J. y Tarrús, J. 2011: El poblat lacustre del neolitic antic de la Draga. Excavacions 2000-2005. Girona. Monografies del Monografies del Centre d'Arqueologia Subaquàtica de Catalunya 9. Girona.

Briois F. y Manen C. 2009: “L'habitat néolithique ancien de Peiro Signado à Portiragnes (Hérault)". En A. Beeching e I. Sénépart I. (eds.): De la maison au village. L'habitat néolithique dans le Sud de la France et le Nord-Ouest méditerranéen (Marseille 2003). Mémoire Société préhistorique française 48. Paris: 31-37.

Cebrià, A.; Fullola, J. M.; Oms, F. X. y Pedro, M. 2017: “Coves sepulcrals (III mil·lenni $\mathrm{aC}$ ) al baix Foix, un patrimonio oblidat i malmès". En M. Boada, R. Maneja y C. Pereira (eds.): IV Trobada d'Estudiosos del Foix (Castellet i la Gornal 2016): 105-115. Sèrie Territori i Parcs Naturals 3. Diputació de Barcelona. Barcelona.

Clop, X. 1996: "Estudio petrológico de las cerámicas cepilladas del neolítico antiguo evolucionado del Penedès". Rubricatum 1, I Congrés del Neolític a la Península Ibèrica (Gavà-Bellaterra 1995): 207-214.

Clop, X.; Faura, J. M.; Piqué, R. y Gibaja, J. F. 2005: “Els Vilars de Tous (Igualada, Barcelona): una estructura de habitación y producción lítica del V ${ }^{\circ}$ milenio cal BC". En P. Arias, R. Ontañón, R. y C. GarcíaMoncó (eds.): III Congreso del Neolítico en la Península Ibérica (Santander 2003): 551-558. Monografías del Instituto Internacional de Investigaciones Prehistóricas de Cantabria 1. Universidad de Cantabria. Santander.

Coularou, J.; Jallet, F.; Colomer, A. y Balbure, J. 2008: Boussargues. Une enceinte chalcolithique des garrigues du Sud de la France. Archives d'écologie préhistorique. Toulouse.

Edo, M.; Antolín, F.; Martínez, P.; Castellana, C.; Bardera, R.; Saña, M.... y Fullola, J. M. 2019: "Cueva de Can Sadurní (Begues, Barcelona). Hacia la definición del modelo funerario”. En J. F. Gibaja, M. Mozota, M. E. Subirà y A. Martín (ed.): Mirando a la muerte: las prácticas funerarias durante el Neolítico en el noreste peninsular. E-ditarx 3. Castelló de la Plana: 306-356.

Esteve, X.; Martín, P.; Oms, F. X.; Jornet, R. y López, D. 2012: “Intervencions arqueològiques als enllaços de 1'autopista AP-7 de Vilafranca del Penedès: nous assentaments prehistòrics a l'aire lliure al Penedès". Tribuna d'Arqueologia 2010-2011: 23-39.

Ferrer, A. 1954: "Les Guixeres de Viloví (Penedés, Barcelona), yacimiento al aire libre del Neolítico Hispano-mauritánico". I Congreso Arqueológico del Marruecos Español (Tetuán 1953): 171-175. Alta Comisaría de España en Marruecos. Tetuán.

Font, J. 2006: "Les estructures del Neolitic final-Calcolitic i del Bronze mitja-recent de Can Vinyalets (Santa Perpetua de Mogoda)". Notes 21: $185-216$

García Atiénzar, G.; Barciela, V.; Martínez Amorós, S.; Jover Maestre, F. J.; Molina, F. J.; Tormo, C.... y Sirvent, L. 2020: "El asentamiento neolítico de Limoneros (Elche, Alicante)". Complutum 31 (1): 25-48. https://doi.org/10.5209/cmpl.71648

García Gazolaz, J. y Sesma, J. 2010: "Enterramientos en el poblado neolítico de los Cascajos (Los Arcos)". En M. A. Hurtado, F. Cañada, J. Sesma y J. García Gasolaz: La tierra te sea leve. Arqueología de la muerte en Navarra. Ed. Gobierno de Navarra. Pamplona: 52-58.

Gernigon, K. 2016: "Les villages avant les maisons? La néolithisation de l'Europe au prisme de la maisonnée". Palethnologie 8. https://doi.org/10.4000/palethnologie.460

Gibaja, J. F.; Oms, F. X.; Mestres, J.; Mazzucco, N. y Palomo, A. 2018: "Primeros resultados sobre la función del utillaje lítico de las prime- ras comunidades neolíticas asentadas en Les Guixeres de Vilobí (Sant Martí Sarroca, Barcelona)". Saguntum PLAV 50: 35-56. https://doi.org/10.7203/sagvntvm.50.11603

Gómez, A. y Molist, M. 2016: "Les primeres ocupacions estables al pla de Barcelona, del VI al IV mil·lenni: el desenvolupament dels agricultors-ramaders". La prehistòria al pla de Barcelona. Documents per a una nova sintesi. Museu d'Historia de Barcelona, Documents 11. Ajuntament de Barcelona. Barcelona: 35-50.

Gómez, A. y Molist, M. 2017: “Caserna de Sant Pau (Barcelona): noves dades pel neolític antic cardial del nord-est peninsular". Cypsela 20: 11-23.

Gonçalves, V. S.; Sousa, A. C. y Marchand, G. 2013: Na margem do grande rio. Os últimos grupos de caçadores-recolectores e as primeiras sociedades camponesas no Guadiana médio. Memórias d'Odiana 2. ${ }^{a}$ Série Estudos Arqueológicos do Alqueva. Évora.

Guilaine, J. 2016: "Maisons néolithiques: exemples méditerranéens". Palethnologie 8. https://doi.org/10.4000/palethnologie.468

Guilaine, J. y Escallon, G. 2004: Les Vautes (Saint-Gély-du-Fesc, Hérault) et la fin du Néolithique en Languedoc oriental. Archives d'Ecologie Préhistorique, Recherches en Archéologie Préventives 2. Toulouse.

Jover, F. J.; Pastor, M. y Torregrosa, P. 2019: “Advances in the analysis of households in the early neolithic groups of the Iberian Peninsula: Deciphering a partial archaeological record". Journal of Anthropological Archaeology 53: 1-21. https://doi.org/10.1016/j.jaa.2018.10.001

Jover, F. J. y Torregrossa, P. 2017: "Las unidades domésticas de los primeros grupos neolíticos en el Este de la península ibérica". Munibe Antropologia-Arkeologia 68: 135-153.

https://doi.org/10.21630/maa.2017.68.03

Laborda, R. 2019: El Neolitico antiguo en el Valle medio del Ebro. Una visión desde la cerámica y las dataciones radiocarbónicas. Monografías Arqueológicas, Arqueología 55. Prensas Universitarias. Zaragoza.

Laborda, R.; Alcolea, M.; Benavente, J. A. y Andrés, T. 2017: "Nuevos datos radiocarbónicos del Neolítico antiguo del Valle Medio del Ebro. El yacimiento de Alonso Norte (Alcañiz, Teruel) en el río Guadalope". Salduie 17: 11-30.

Martín, A.; Edo, M.; Tarrús, J. y Clop, X. 2010: "Le Néolithique ancien de Catalogne (VI - première moité du V millenaire av. J. C.). Les séquences chronoculturels". En C. Manen, F. Convertini, D. Binder e I. Sénépart (eds.): Premières societés paysannes de Méditerrannée occidental. Structures des productions céramiques. Mémoire 51 Société Préhistorique Française. Toulouse: 197-214.

Mestres, J. 1981-1982: "Avançament a l'estudi del jaciment de Les Guixeres de Vilobí”. Pyrenae 17-18: 35-53.

Mestres, J. 1987: "La indústria lítica en sílex del neolític antic de Les Guixeres de Vilobí)". Olerdulae XII, 1-4: 5-71.

Mestres, J. y Esteve, X. 2016: "Sitges, cenotafis i sepulcres. 20 anys d'intervencions arqueològiques al Penedès". En X. Esteve, C. Miró, N. Molist y G. Sabaté (eds.): Jornades d'Arqueologia del Penedès (Vilafranca del Penedès 2011): 3-27. Institut d'Estudis Penedesencs. Vilafranca del Penedès.

Mestres, J. y Tarrús, J. 2009: "Hábitats neolíticos al aire libre en Catalunya”. En De Méditerranée et d'ailleurs...Mélanges offerts à Jean Guilaine. Archives d'Écologie Préhistorique. Toulouse: 522-532.

Miró, J. M. 1992: "La fauna del jaciment de Les Guixeres de Vilobí (Alt Penedès) en el context del Neolític Antic a Catalunya". Estat de la investigació sobre el Neolític a Catalunya, $9^{e}$ Col-loqui Internacional d'Arqueologia de Puigcerdà (Puigcerdà, 1991): 79-84. Publicacions de l'Institut d'Estudis Ceretans. Andorra.

Oms, F. X. 2014: La neolitizació del nord-est de la Península Ibèrica a partir de les datacions de $14 \mathrm{C}$ i les primeres ceràmiques impreses $c$. 5600-4900 cal BC. Tesis doctoral, Universitat de Barcelona. http://hdl.handle.net/2445/69672

Oms, F. X. 2017: "Fases y territorios de la neolitización del NE de la Península Ibérica ca. 5600-4900 cal BC". Munibe Antropologia-Arkeologia 68: 155-177. https://doi.org/10.21630/maa.2017.68.01

Oms, F. X.; Esteve, X.; Mestres, J.; Martin, P. y Martins, H. 2014: "La neolitización del nordeste de la Península Ibérica: datos radiocarbónicos y culturales de los asentamientos al aire libre del Penedès". Trabajos de Prehistoria 71 (1): 43-56. https://doi.org/10 .3989/tp .2014.12123 
Oms, F. X. y Martín, A. 2018: "Els primers pagesos i ramaders del nordest de la Península Ibèrica: el Neolític ca. 5600-2300 cal BC". Monografies del Museu d'Arqueologia de Catalunya 2. Barcelona: 37-62.

Oms, F. X.; Martín, A.; Esteve, X.; Mestres, J.; Morell, B.; Subirà, M. E. y Gibaja, J. F. 2016: "The Neolithic in northeast Iberia: chronocultural phases and 14C". Radiocarbon 58 (2): 291-309. https://doi.org/10.1017/rdc.2015.14

Oms, F. X.; Mestres, J.; Cebrià, A.; Morales, J. I.; Mendiela, S. y Pedro, M. 2018: "Primers resultats sobre la seqüència del neolític final al bronze final c. 3350-900 cal. aC a la Cova de la Guineu (Font-rubí, Alt Penedès, Barcelona)". Tribuna d'Arqueologia 2014-2015: 254266.

Pallarés, M.; Bordas, A. y Mora, R. 1997: "El proceso de neolitización en los Pirineos Orientales. Un modelo de continuidad entre los cazadores-recolectores neolíticos y los primeros grupos agropastoriles". Trabajos de Prehistoria 54 (1): 121-141. https://doi.org/10.3989/tp.1997.v54.i1.382

Pérez-Jordá, G.; Bernabéu, J.; Carrión-Marco, Y.; García-Puchol, O.; Molina, Ll. y Gómez-Puche, M. (eds.) 2011: La Vital (Gandia, Valencia). Vida y muerte en la desembocadura del Serpis durante el III y el I milenio a.C. Serie de Trabajos Varios 113. Servicio de Investigaciones Prehistóricas. Valencia.

Perrin, T.; Manen, C. y Séjalon, P. 2014: Le Néolithique ancien de la plaine de Nimes (Gard, France). Ed. Archives d'Écologie Préhistorique. Toulouse.

Pessina, A. y Tiné, V. 2010: Archeologia del Neolitico. L'Italia tra VI e IV millennio a.C. Carossi Editore. Roma.

Pou, R.; Martí, M. y Gibaja, J. F. 2005: "Les restes del Neolític antic al carrer d'en Xammar (Mataró, Maresme)". Laietània 16: 9-23.

Prats, G.; Antolín, F. y Alonso, N. 2020: "From the earliest farmers to the first urban centres: a socio-economic analysis of underground storage practices in north-eastern Iberia". Antiquity 94: 653-668. https://doi.org/10.15184/aqy.2019.153

Reimer, P. J., Austin, W. E. N., Bard, E., Bayliss, A., Blackwell, P. G., Bronk Ramsey, C. y Talamo, S. 2020. "The IntCal20 Northern hemisphere radiocarbon age calibration curve (0-55 ka BP)". Radiocarbon 62 (4): 725-757. https://doi.org/10.1017/RDC.2020.41

Rodà, X.; Roy, M.; Griera, R.; Vega, S.; Plasencia, X.; Martínez-Moreno, J. y Mora, R. 2019: "Fora de la norma? Mesolític i Neolític antic a la Font del Ros". Actes de les IV Jornades d'Arqueologia de la Cata- lunya Central (Solsona 2016): 31-37. Museu Diocesà i Comarcal de Solsona. Solsona.

Roig. J.; Coll, J. M.; Molina, J. A. y Gómez, R. 2020: "El poblat neolític de Ca l'Estrada-2 (Canovelles, Vallès Oriental)". Tribuna d'Arqueologia 2016-2017: 217-239.

Rojo; M. A., Kunst, M., Garrido, R., García, I. y Morán, G. 2008. Paisajes de la memoria. Asentamientos del Neolitico Antiguo en el Valle de Ambrona (Soria, España). Serie Arte Arqueología. Universidad de Valladolid. Valladolid.

Rojo, M. A; García-Martínez de Lagrán, I. y Royo, J. I. 2018: “The beginning of the Neolithic in the mid-Ebro valley and in Iberia's inland (northern and southern Submeseta), Spain". Quaternary International 470: 398-438. https://doi.org/10.1016/j.quaint.2017.12.037

Rosser, P. y Soler, S. 2016: "Propuesta de fases cronológicas para el asentamiento neolítico del Tossal de les Basses (Alicante, España)". Del neolitic a l'edat del bronze en el Mediterrani occidental. Estudis en homenatge a Bernat Marti Oliver. Serie de Trabajos Varios, Servicio de Investigaciones Prehistóricas 119. Diputación de Valencia. Valencia: $225-248$

Sénépart, I. 2000: "Gestion de l'espace au Néolithique ancien dans le Midi de la France: l'exemple du Baratin à Courthézon (Vaucluse)" En M. Leduc, N. Valdeyron y J. Vaquer (eds.): Sociétés et espaces, Rencontres méridionales de Préhistoire Récente, $3^{e}$ sesión (Toulouse 1998): 44-51. Éd. Archives d'Écologie Préhistorique. Toulouse.

Sénépart I. 2003: "Les structures empierrées de Baratin (Courthézon, Vaucluse): bilan descriptive". Le feu domestique et ses structures au Néolithique et à l'Âge des Métaux". Actes du colloque de Beaune et Bourg-en-Bresse 2000: 231-244. Collection Préhistoire 9, Monique Mergoil. Montagnac.

Sénépart I. 2009: "L'habitat néolithique ancien cardial du Baratin à Courthézon (Vaucluse)". En A. Beeching e I. Sénépart I. (eds.): De la maison au village. L'habitat néolithique dans le Sud de la France et le Nord-Ouest méditerranéen (Marseille 2003): 61-72. Mémoire Société préhistorique française 48. Paris.

Tarrús, J. (ed.) 2017: El poblat neolitic de Ca n'Isach (Palau-saverdera, Alt Empordà): les excavacions de 1987-1994 i 2001-2003. Sèrie monogràfica 27. Museu d'Arqueologia de Catalunya-Girona. Girona.

Torregrosa, P.; Jover Maestre, F. J. y López-Seguí, E. 2011: Benàmer (Muro d'Alcoi, Alicante) Mesoliticos y neolíticos en las tierras meridionales valencianas. Serie de Trabajos Varios 112. Diputación de València. València.

Trab. Prehist., 78, N. ${ }^{\circ}$ 2, julio-diciembre 2021, pp. 257-276, ISSN: 0082-5638

https://doi.org/10.3989/tp.2021.12275 